\title{
Expression of Tau Produces Aberrant Plasma Membrane Blebbing in Glial Cells Through RhoA-ROCK-Dependent F-Actin Remodeling
}

\author{
Francisco M. Torres-Cruz ${ }^{\mathrm{a}}$, Fanny Rodríguez-Cruz ${ }^{\mathrm{a}}$, Jaime Escobar-Herrera ${ }^{\mathrm{a}}$, \\ Norma Barragán-Andrade ${ }^{\mathrm{a}}$, Gustavo Basurto-Islas ${ }^{\mathrm{b}}$, Daniela Ripova ${ }^{\mathrm{c}}$, Jesús Ávila ${ }^{\mathrm{d}}$ \\ and Francisco Garcia-Sierra ${ }^{\mathrm{a}, *}$ \\ ${ }^{a}$ Department of Cell Biology, Center of Research and Advanced Studies of the National Polytechnic Institute \\ (CINVESTAV), Mexico City, Mexico \\ ${ }^{\mathrm{b}}$ División de Ciencias e Ingenierías, Universidad de Guanajuato, Guanajuato, Mexico \\ ${ }^{\mathrm{c}}$ National Institute of Mental Health, Klecany, Czech Republic \\ ${ }^{\mathrm{d}}$ Centro de Biología Molecular Severo Ochoa (CSIC-UAM) Universidad Autónoma de Madrid, Spain
}

Accepted 29 January 2016

\begin{abstract}
Abnormal aggregation of Tau in glial cells has been reported in Alzheimer's disease (AD) and other tauopathies; however, the pathological significance of these aggregates remains unsolved to date. In this study, we evaluated whether fulllength Tau (Tau441) and its aspartic acid ${ }^{421}$-truncated Tau variant (Tau421) produce alterations in the normal organization of the cytoskeleton and plasma membrane (PM) when transiently expressed in cultured C6-glial cells. Forty-eight hours posttransfection, abnormal microtubule bundling was observed in the majority of the cells, which expressed either Tau441 or Tau421. Moreover, both variants of Tau produced extensive PM blebbing associated with cortical redistribution of filamentous actin (F-Actin). These effects were reverted when Tau-expressing cells were incubated with drugs that depolymerize F-Actin. In addition, when glial cells showing Tau-induced PM blebbing were incubated with inhibitors of the Rho-associated protein kinase (ROCK) signaling pathway, both formation of abnormal PM blebs and F-Actin remodeling were avoided. All of these effects were initiated upstream by abnormal Tau-induced microtubule bundling, which may release the microtubule-bound guanine nucleotide exchange factor-H1 (GEF-H1) into the cytoplasm in order to activate its major effector RhoA-GTPase. These results may represent a new mechanism of Tau toxicity in which Tau-induced microtubule bundling produces activation of the Rho-GTPase-ROCK pathway that in turn mediates the remodeling of cortical Actin and PM blebbing. In AD and other tauopathies, these Tau-induced abnormalities may occur and contribute to the impairment of glial activity.
\end{abstract}

Keywords: F-Actin remodeling, glial degeneration, membrane blebbing, Rho associated protein kinase, RhoGTPases, Tau, tauopathies

*Correspondence to: Francisco Garcia-Sierra, Department of Cell Biology, Center of Research and Advanced Studies of the National Polytechnic Institute (CINVESTAV-IPN), Av. Instituto Politécnico Nacional 2508, CP 07360 México, D.F., México. Tel.: +52 555747 3354; Fax: +52 5557473393 ; E-mails: fgs516@ yahoo.com and fgarcia-sierra@cell.cinvestav.mx.

\section{INTRODUCTION}

It has been long documented that accumulation of fibrillary and nonfibrillary aggregates of Tau is a common neuropathological feature of Alzheimer's disease (AD) $[1,2]$ and of several types of subcortical 
dementias referred to as tauopathies [3]. In these disorders, not only are neurons affected by Tau aggregation, but this also occurs in several populations of glial cells, including astrocytes $[4,5]$, oligodendrocytes $[3,6]$, and microglia $[7,8]$.

From a physiological viewpoint, the formation of intracellular inclusions of Tau in glial cells might rely on the same mechanisms as in neuronal cells, thus entailing the same pathologic consequences. If so, degeneration of glial cells may also affect neuronal functioning and survival.

To further understand the mechanisms that underlie neurodegeneration caused by accumulation of Tau, in addition to several phosphorylated, mutated, or truncated Tau variants, overexpression of these entities in neuronal and non-neuronal cells has revealed several alterations in cell functioning prior to death [9-14].

Truncation of Tau at $\mathrm{Asp}^{421}$ has been considered a relevant modification that increases the capacity of Tau to polymerize in vitro, but additionally composing the majority of neurofibrillary pathology in $\mathrm{AD}$ brains [15-17]. When this truncated variant of Tau was expressed in neurons, alterations in the functioning of several organelles, including mitochondria and the endoplasmic reticulum, was observed [10, 11]. Previously, we transiently expressed full-length Tau (Tau441) and Aspartic acid $^{421}$-truncated Tau (Tau421) in SH-SY5Y cells and in addition to alterations in the nuclear morphology, we observed increased microtubule bundling [18]. Overexpression of Tau and its capacity to promote microtubule bundling has been reported previously, but this capacity has been widely associated with physiological processes such as neuritic outgrowing and stability $[19,20]$. In contrast, other reports on Chinese hamster ovary $(\mathrm{CHO})$ cells $[21$, 22] and N2a neuroblastoma cells [23] concluded that overexpression of Tau inhibits kinesin-dependent trafficking of vesicles and disturbs the organization of intermediate filaments. Despite that some evidences of Tau-Actin interactions in vitro [24-27] and in cell systems [28-31] have been documented, little is known about any relationship under pathological conditions, with the exception of evidence that abnormally phosphorylated Tau produces neurodegeneration with the accumulation of filamentous Actin (F-Actin) and the formation of Actin-rich rods in Drosophila and mouse models [32]. From these findings, it was proposed that direct interaction between Tau and Actin may occur and mediate Tau-induced neurotoxicity in AD and related disorders. On the other hand, in platelet-derived growth factor (PDGF)-stimulated 3T3-fibroblasts, the expression of Tau altered the remodeling of Actincytoskeleton through a mechanism in which Tau interacts with Src, which upregulates Src-tyrosine kinase activity and Src-dependent Actin remodeling [33].

Regarding the pathological significance of Tau accumulation inside glial cells, few reports have sought evidence of abnormalities by using the Tauexpressing cell approach. To contribute to this, primary cultured astrocytes from rat brains were adenoviral-vector-transfected to induce overexpression of the full-length Tau [34]. In this study, Tau produced an increase of microtubule bundling, but a selective reduction of stable detyrosinated microtubules. This effect was followed by alteration in the kinesin-dependent trafficking of organelles, Golgi apparatus fragmentation, and finally, cell death [34]. In contrast, transient overexpression of full-length Tau in cultured rat microglial cells produced an increase of Iba1, migration, and phagocytosis, all indicators of an activated state [35]. This physiological activation was also associated with the secretion of several interleukins, tumor necrosis factor-alpha (TNF- $\alpha$ ), and nitric oxide (NO).

Due to the limited and contradictory information with respect to the pathological role of Tau in glial cells, we searched for more convincing evidence to clarify this unsolved issue. The data that we reported here indicate that transient expression of either Tau441 or Tau421 in C6-glial cells produces extensive microtubule bundling and abnormal blebbing of the plasma membrane (PM). These blebs may alter diverse physiological properties of the PM. Cell migration in a scratch-wound assay was altered in Tau-expressing C6-glial cells. To acquire insights into the plausible mechanism underlying these abnormalities, we found that the formation of PM blebs depends on remodeling of the F-Actin cytoskeleton, which is regulated upstream by the activation of RhoA (a small GTPase) and Rho-associated protein kinase (ROCK) signaling. All of these effects were initiated upstream by Tau-induced microtubule bundling, which may release microtubule-bound Guanine nucleotide exchange factor-H1 (GEF-H1) into the cytoplasm in order to activate its major effector, RhoA-GTPase. Taken together, these results may represent a new mechanism of Tau toxicity that contributes to the impairment of glial activity and neuronal dysfunction reported in $\mathrm{AD}$ and other tauopathies. 


\section{MATERIALS AND METHODS}

\section{Plasmid constructs}

Plasmid preparation was described in our previous report [18]. Prior to transfection experiments, the integrity of pcDNA3.1 Zeo (-) plasmids containing the sequence to express either Tau441 or Tau421, as well as the empty vector, was confirmed by double sequence analysis. Green fluorescent protein (GFP)fused Tau was produced from the pVLGT42 plasmid (GFP-Tau441).

\section{Cell culture and transfection}

The C6-glial cell line obtained from American Type Culture Collection (ATCC) (Manassas, VA, USA) was grown in Dulbecco's Modified Eagle Medium (DMEM-F12); glucose (1/1) medium supplemented with $5 \%$ fetal bovine serum (FBS) (GIBCO-Life Technologies, Grand Island, NY, USA), $2 \mathrm{mM} \mathrm{L-glutamine,} \mathrm{and} 100 \mathrm{U} / \mathrm{mL}$ penicillin, $100 \mu \mathrm{g} / \mathrm{mL}$ streptomycin, and was maintained under a humidified atmosphere of $5 \% \quad \mathrm{CO}_{2}$ at $37^{\circ} \mathrm{C}$. When this reached $50-60 \%$ confluence, C6-glial cells were changed to FBS-free Optimem specialized medium (GIBCO-Invitrogen) for $15 \mathrm{~min}$ and was then transiently transfected with the Tau constructs (plasmid pcDNA 3.1 Zeo (-), which contain the sequences for either Tau441 or Tau421, and plasmid pVLGT42, which contains the sequence for GFP-Tau441 by using the Lipofectamine ${ }^{\circledR}$-PLUS ${ }^{\mathrm{TM}}$ reagent following the manufacturer's instructions (Invitrogen-Life Technologies, Carlsbad, CA, USA). Three $h$ after transfection, the cells were post-incubated in fresh DMEM-F12 medium supplemented with 5\% FBS and maintained for $48 \mathrm{~h}$ at $37^{\circ} \mathrm{C}$. Thereafter, transfected cells were washed in ice-cold Phosphate buffered saline (PBS) $\mathrm{pH} 7.4$ and processed for the different assays as described later. Under this protocol we obtained a transfection efficiency of $40 \%$.

\section{Cell viability}

The 3- (4, 5-diMethylThiazol-2-yl)-2, 5-diphenyl Tetrazolium bromide (MTT) assay (Sigma-Aldrich, St. Louis, MO, USA) was employed to evaluate cell viability. This technique determines the ability of healthy cells to produce formazan from the cleavage of the MTT tetrazolium ring [36]. Briefly, enzyme-linked immunosorbent assay (ELISA) plates with both transfected and non-transfected cells were washed with fresh culture medium and then incubated in fresh medium containing MTT $(0.5 \mathrm{mg} / \mathrm{mL})$ for $3 \mathrm{~h}$ at $37^{\circ} \mathrm{C}$. The MTT medium was discarded and the cells were incubated in Dimethyl sulfoxide (DMSO) to dissolve the formazan aggregates. The intensity of the MTT products was read at $570 \mathrm{~nm}$ utilizing an ELISA microplate reader (iMark; Bio-Rad Laboratories, Inc., Hercules, CA, USA).

\section{Immunofluorescence and confocal microscopy}

For double, triple, and multiple immunofluorescence, transfected and non-transfected C6-glial cells were fixed with $4 \%$ paraformaldehyde in PBS $(\mathrm{pH}$ 7.4) at room temperature (RT) for $15 \mathrm{~min}$ and then permeabilized in $0.1 \%$ Triton X-100-PBS (PBSt). After blocking for $15 \mathrm{~min}$ at RT (in $0.5 \%$ gelatin and $1.5 \%$ FBS in PBS), cells were incubated with a variety of antibodies in pair-wise combinations, always mixing one mouse monoclonal-IgG with one rabbit polyclonal-IgG to avoid crosstalk and non-specific cross-reactions. Primary antibody incubations were conducted for $1 \mathrm{~h}$ at RT. Antibody specifications are described in Table 1. Pair-wise combinations, as well as multiple labeling with fluorescent markers, are depicted in the figures. Secondary antibodies corresponding to mouse-IgG and rabbit polyclonal IgG were tagged with either FluoresceinIsoThioCyanate (FITC) (Jackson ImmunoResearch Laboratories, Inc., West Grove, PA, USA) or TetramethylRhodamine-IsoThioCyanate (TRITC $^{\circledR}$ ) (Jackson ImmunoResearch Laboratories, Inc.) and incubated simultaneously in PBSt for $1 \mathrm{~h}$ at RT ( $1: 100$ dilution) in a humidity chamber. In some experiments, multilabeling was performed by including the Hoechst-33258 fluorescent nuclear marker (Invitrogen Molecular Probes, Eugene, Oregon, USA) and Rhodamine-phalloidin a highaffinity F-Actin probe conjugated to the red-orange fluorescent dye, TRITC (Invitrogen Molecular Probes).

For C6-glial cells transfected with GFP-Tau441, fixation was carried out in $100 \%$ methanol at $-20^{\circ} \mathrm{C}$ for $5 \mathrm{~min}$ and incubated with a pair-wise combination of a monoclonal antibody to $\alpha$-Tubulin and one rabbit polyclonal antibody to GEF-H1 (GeneTex, Inc., Irvine, CA, USA) (see Table 1). Cyanine-5 (Cy5)-tagged anti-mouse IgG and TRITC-tagged anti-rabbit IgG (Jackson ImmunoResearch Laboratories, Inc.) were employed as secondary antibodies $(1: 100)$. These cells were also counterstained with 
Table 1

Antibodies and fluorescent markers employed

\begin{tabular}{|c|c|c|c|c|c|}
\hline Antibody & Epitope & Host-class & Procedure & Dilution & Source of reference \\
\hline Tau-5 & $210-230^{* *}$ & mouse-IgG & $\mathrm{IC}, \mathrm{WB}$ & $1: 500$ & [76] \\
\hline Tau & Tau & polyclonal rabbit-IgG & IC & $1: 1000$ & GeneTex, Inc., Irvine, CA, USA \\
\hline$\alpha$-Tubulin & $\alpha$-Tubulin & mouse-IgG & IC & $1: 500$ & $\begin{array}{l}\text { Santa Cruz Biotechnology, Inc., } \\
\text { Dallas, TX, USA }\end{array}$ \\
\hline Truncated-PARP & $\mathrm{Asp}^{214}$-truncation & polyclonal rabbit-IgG & WB & $1: 1000$ & $\begin{array}{l}\text { Cell Signaling Technology, } \\
\text { Danvers, MA, USA }\end{array}$ \\
\hline$\alpha$-Actin & $\alpha$-Actin & polyclonal rabbit-IgG & WB & $1: 500$ & {$[77]$} \\
\hline GEF-H1 & GEF-H1 & polyclonal rabbit-IgG & IC & $1: 500$ & GeneTex, Inc. \\
\hline GAPDH & GAPDH & mouse-IgG & WB & $1: 10000$ & Millipore, Tamecula, CA, USA \\
\hline Organelle & $\begin{array}{l}\text { Fluorescent } \\
\text { marker }\end{array}$ & $\begin{array}{l}\text { Excitation/ } \\
\text { emission (nm) }\end{array}$ & Procedure & Dilution & Source of reference \\
\hline Nuclei & Hoechst-33258 & $(350-461)$ & FL & $1: 2000$ & $\begin{array}{l}\text { Invitrogene Molecular Probes, } \\
\text { Eugene, OR, USA }\end{array}$ \\
\hline F-Actin cytoskeleton & Rhodamine-phalloidin & $(540-565)$ & FL & $1: 500$ & Invitrogene Molecular Probes \\
\hline
\end{tabular}

IC, immunocytochemistry; WB, western blotting; FL, fluorescence. ${ }^{* *}$ Residues based on the longest human Tau isoform (2N4R).

Hoechst-33258 to visualize the nuclei. In some experiments, Tau-expressing C6-glial cells were incubated with RhoA, ROCK, and Myosin II ATPase activity inhibitors (C3-transferase, Y-27632, and Blebbistatin, respectively) (Cytoskelenton Inc., Denver, CO, USA; Tocris Bioscience, Bristol, UK and Sigma Aldrich, respectively) [37, 38] and, based on Tau, F-Actin, Tubulin, and nuclei staining, some changes in cytoskeletal and PM organization were analyzed. Immunolabeled cells were commonly analyzed by epifluorescence through a 20X (Numerical aperture [NA]: 0.5) and a 40X (NA: 0.75) Nikon PlanFluor lens coupled to a Nikon Eclipse-80i Microscope (Nikon Corp., Tokyo, Japan). The images were obtained and collected by using a Nikon digital sightDG-Ril camera controlled with the NIS-Elements AR-3.0-SP7 software included in the system (Nikon Corp.). Quantitative counting of fluorescent cells was conducted at low magnification in recorded images. For multiple labeling, optical sectioning, colocalization, and critical observations of subcellular components, images were collected in a TCS-SP8 confocal laser-scanning microscope by using a $63 \mathrm{X}$ (NA: 1.4) OIL PH3 CS2 HC PL APO lens (Leica Microsystems, Heidelberg, Germany).

\section{Analysis of cells extracts by electrophoresis and western blotting}

After cell transfection and treatments with some drugs, the cell cultures were washed twice with PBS, scraped and lysed in Radio-Immuno-PrecipitationAssay (RIPA) buffer containing a cocktail of proteases inhibitors $(150 \mathrm{mM} \mathrm{NaCl}, 50 \mathrm{mM}$ TRIS, $\mathrm{pH}$ 8.0, $1 \%$ Triton $\mathrm{X}-100,0.5 \%$ sodium deoxycholate,
$1 \mathrm{mM}$ PMSF, $100 \mathrm{mM} \mathrm{NaF}, 1 \mathrm{mM} \mathrm{Na} \mathrm{VO}_{4}$, and $2 \mu \mathrm{g} / \mathrm{mL}$ Complete; Roche, Indianapolis, IN, USA) and centrifuged for $10 \mathrm{~min}$ at $12,000 \mathrm{~g}$. In some experiments, non-transfected cells were previously treated with either $1 \mu \mathrm{M}$ staurosporine (STS) (SigmaAldrich) or $1 \mu \mathrm{g} / \mathrm{mL}$ Actinomycin-D (Act-D) for $12 \mathrm{~h}$ to induce apoptosis, and then lysed and processed in the same manner. The supernatant was collected and the protein content in the samples was determined by means of the Mini-Bradford assay utilizing the BioRad protein assay reagent (Bio-Rad Laboratories, Inc.). Total extracts of the cells containing $30 \mu \mathrm{g}$ of protein were mixed in $2 \mathrm{X}$ sample buffer (TRIS-HCL $100 \mathrm{mM}$ pH 6.8, sodium dodecyl sulfate (SDS) $4 \%$, bromophenol blue $0.2 \%, \beta$-mercaptoethanol $5 \%$, and glycerol 20\%) and boiled at $95^{\circ} \mathrm{C}$ for $5 \mathrm{~min}$. Proteins from the samples were separated by electrophoresis on 8-10\% SDS-polyacrylamide gel (SDS-PAGE) and then transferred onto a nitrocellulose membrane for immunoblotting analysis. Membranes were blocked in 5\% nonfat dried milk in PBS-tw (PBS-0.1\% Tween 20) overnight at $4^{\circ} \mathrm{C}$. All primary antibodies (see Table 1) were diluted in PBS-tw and incubated at RT for $1 \mathrm{~h}$. After washing in PBS-tw, incubation with the corresponding peroxidase-conjugated secondary antibody to either mouse or rabbit $(1: 10,000$; ZYMED Invitrogen, Carlsbad, CA, USA) was carried out for $1 \mathrm{~h}$ in PBS-tw. Bands of immunoreactive proteins were visualized after membrane incubation in Western Lightning ${ }^{\circledR}$ Plus-ECL Enhanced Chemiluminescence Substrate (PerkinElmer, Inc., Waltham, MA, USA) and developed on autoradiography films (Kodak Medical X-ray, general-purpose-blue; Eastman Kodak Co., Rochester, NY, USA) according to the manufacturer's instructions. 


\section{TUNEL assay}

To determine whether Tau affects the survival of C6-cells, the Terminal deoxynucleotidyl transferasemediated dUTP Nick End Labeling (TUNEL) was performed by using In Situ Cell Death Detection Kit (ROCHE Applied Science, Mannheim, Germany). Briefly, cells were transfected with the empty vector and incubated for $12 \mathrm{~h}$ in the presence of STS $(1 \mu \mathrm{M})$ to induce chemical apoptosis. The cells were fixed with $4 \%$ formaldehyde for $1 \mathrm{~h}$ at RT, rinsed twice in PBS, and permeabilized with $0.1 \%$ Triton X-100 in freshly prepared $0.1 \%$ sodium citrate for $2 \mathrm{~min}$ on ice. After rinsed twice in PBS, the coverslips were incubated with TUNEL reaction mixture for $15 \mathrm{~min}$ at $37^{\circ} \mathrm{C}$, and then incubated with Tau 46.1 antibody to detect Tau. The coverslips were rinsed with PBS and incubated with Hoechst-33258 for $5 \mathrm{~min}$ and mounted with Vectashield.

\section{Scratch-wound assay}

C6-glial cells were grown to confluence on $15.6 \mathrm{~mm}$ culture dishes, transfected for $48 \mathrm{~h}$ and treated for $2 \mathrm{~h}$ with $12 \mu \mathrm{M}$ mitomycin $\mathrm{C}$ to inhibit proliferation during the experiment. Cell cultures were scratch-wounded using a sterile $10 \mu$ pipette tip, washed twice with PBS and re-fed with DMEM-F12 with $10 \%$ FBS. After 48 h, C6-cells were fixed and the progress of cell migration into the wounded area was observed by immunofluorescence with antibodies to Tau (polyclonal) and $\alpha$-Tubulin (mouse monoclonal).

\section{RESULTS}

\section{Transient expression of Tau alters the normal morphology and the Tubulin cytoskeleton of C6-glial cells}

Tau expression was induced in C6-glial cells to evaluate alterations in cell morphology and the disturbance of the intracellular organization of the cytoskeleton. The expression of either Tau441 or Tau421, which is a proteolytic product of Caspase-3 action [17], was confirmed by immunofluorescence (Fig. 1A, B) and immunoblot analysis (Fig. 1D) in $48 \mathrm{~h}$ post- and non-transfected C6-glial cells (transfection efficiency around 40\%). A polyclonal antibody to either variant of Tau, in combination with a monoclonal antibody to $\alpha$-Tubulin, was utilized for immunofluorescence analysis. C6 cells transfected with the empty vector were not recognized by the polyclonal antibody to Tau (left panel, Fig. 1A), which indicates the absence of endogenous expression of the Tau in these glial cells. Immunoblot analysis with the Tau-5 antibody, which recognizes residues 210-230 in the molecule of Tau (see Table 1) also confirmed the lack of endogenous expression of Tau in both normal cells and in cells only transfected with the empty vector (pcDNA3.1) (Fig. 1D). For extracts of cells expressing either Tau441 or Tau421, Tau-5 recognizes the corresponding bands of $65 \mathrm{kDa}$ and $63 \mathrm{kDa}$, respectively. Expression of Tau441 and Tau421 was also corroborated by using Tau-46.1 and Tau-C3 antibodies, which specifically recognize the intact C-terminus and $\mathrm{Asp}^{421}$-truncation in the molecule, respectively (data not shown).

In culture, C6-glial cells display a normal spindlelike morphology with radiating distribution of microtubules along the cytoplasm (white arrows, Fig. 1A, B). In contrast, when C6 cells expressed either Tau441 or Tau421, severe morphological changes were observed, such as the formation of PM blebs along the entire cell surface (yellow arrows, Fig. 1A, B). In the majority of Tau-expressing cells, morphological change was also accompanied by abnormal bundling of the Tubulin cytoskeleton (arrowheads, Fig. 1A, B). These microtubule bundles were commonly observed in the vicinity of the nuclear region (arrowheads, Fig. 1B), which we previously reported as also occurring in Tau-transfected SH-SY5Y cells [18]. We found that $84 \%$ (Standard deviation [SD], $\pm 1.5 \%$ ) of Tau-expressing cells develop PM blebs (Fig. 1C). Likewise, when the number of cells exhibiting PM blebs was compared and analyzed by Student $t$ test, no difference was found between Tau441-expressing or Tau421-expressing cells $(p=0.4641$; Not significant $[\mathrm{NS}])$.

When Tau-expressing cells were viewed through differential interference contrast (DIC) microscopy, the manner in which these cells acquired deformed multilobular morphology was noticeable (arrows, Fig. 2A), in comparison with the flat shape displayed by non-transfected cells. The lack of induced apoptosis in Tau-expressing cells was evidenced by negative staining with the TUNEL assay (Fig. 2B, C). After $48 \mathrm{~h}$ of transfection, cell viability was evaluated by using the MTT assay and expression of either Tau441 or Tau421 in C6-glial cells did not decrease this parameter when compared with empty vectortransfected cells $(p=0.803$ by one-way Analysis of variance [ANOVA]) (Fig. 2D). Even after $72 \mathrm{~h}$ of transfection, no difference was found between these groups. 
A
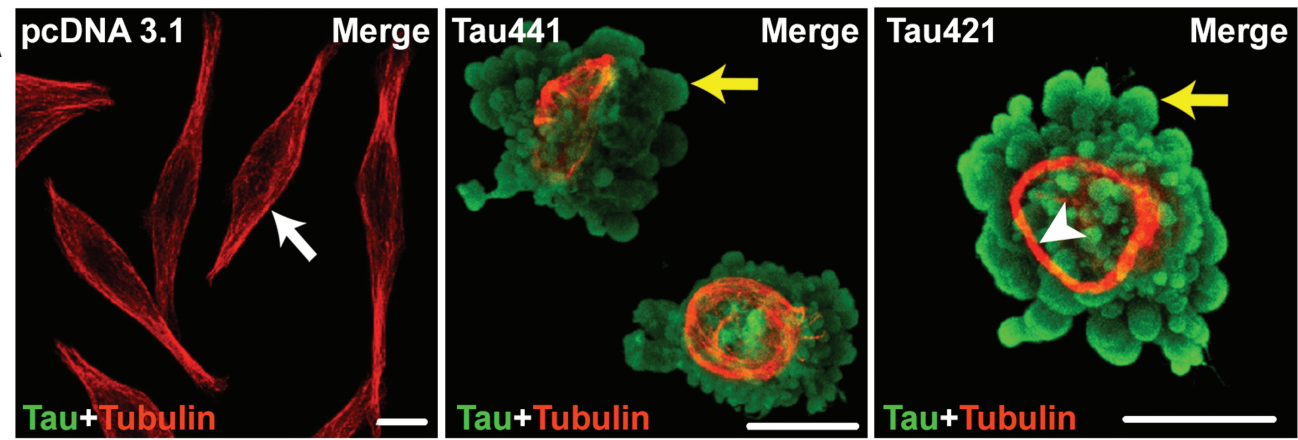

B
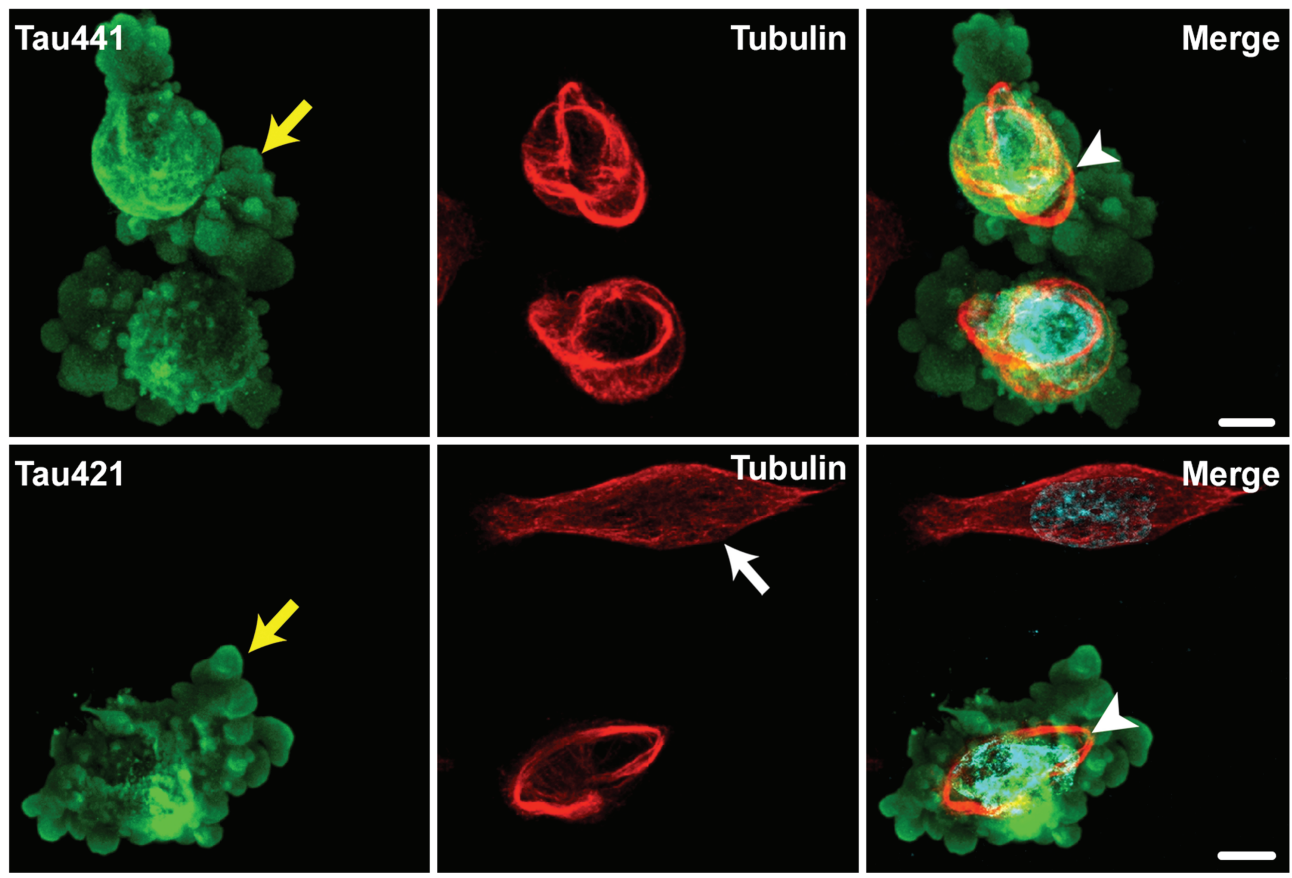

C

Tau441- expressing cells

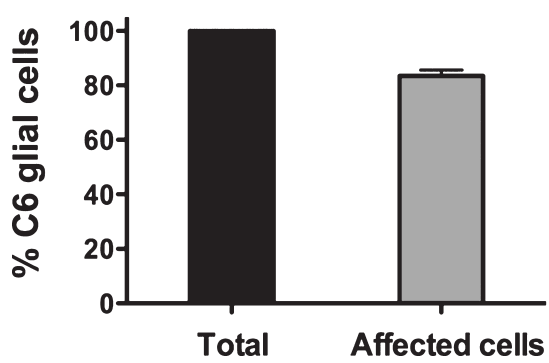

D

\section{Ctrl pcDNA Tau441 Tau421}

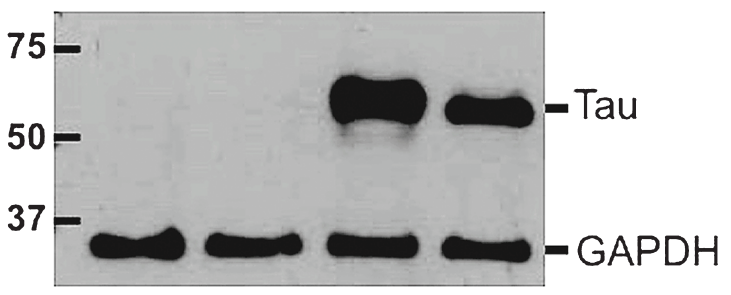

Fig. 1. Altered phenotype of Tau-expressing C6-glial cells. Full-length Tau (Tau441) and Asp ${ }^{421}$-truncated Tau (Tau421) were transiently expressed in C6-glial cells. In A, images represent the merge channels of double immunolabeling assay for Tau variants (green) and Tubulin (red). Immunofluorescence was conducted with a rabbit polyclonal antibody to Tau and a monoclonal antibody to $\alpha$-Tubulin (see Table 1). pcDNA3.1: empty vector. Panel B displays individual channels where the same combination of antibodies was utilized. In the merge channel, nuclear labeling with Hoechst-33258 was also included. Normal Tubulin cytoskeleton in non-transfected cells is indicated with white arrows. Note the formation of pericentric rings of microtubules (arrowheads) and PM blebs (yellow arrows) in Tau-expressing cells. This abnormal phenotype was observed in $84 \%$ of Tau441-expressing cells (affected cells in C). D) Western blotting analysis with Tau-5 antibody (see Table 1) confirms the expression of both Tau 441 and Tau 421 variants of Tau, and the absence of these proteins in control and non-transfected C6-glial cells. Scale bars: $15 \mu \mathrm{m}$ in A, and $10 \mu \mathrm{m}$ in B. 

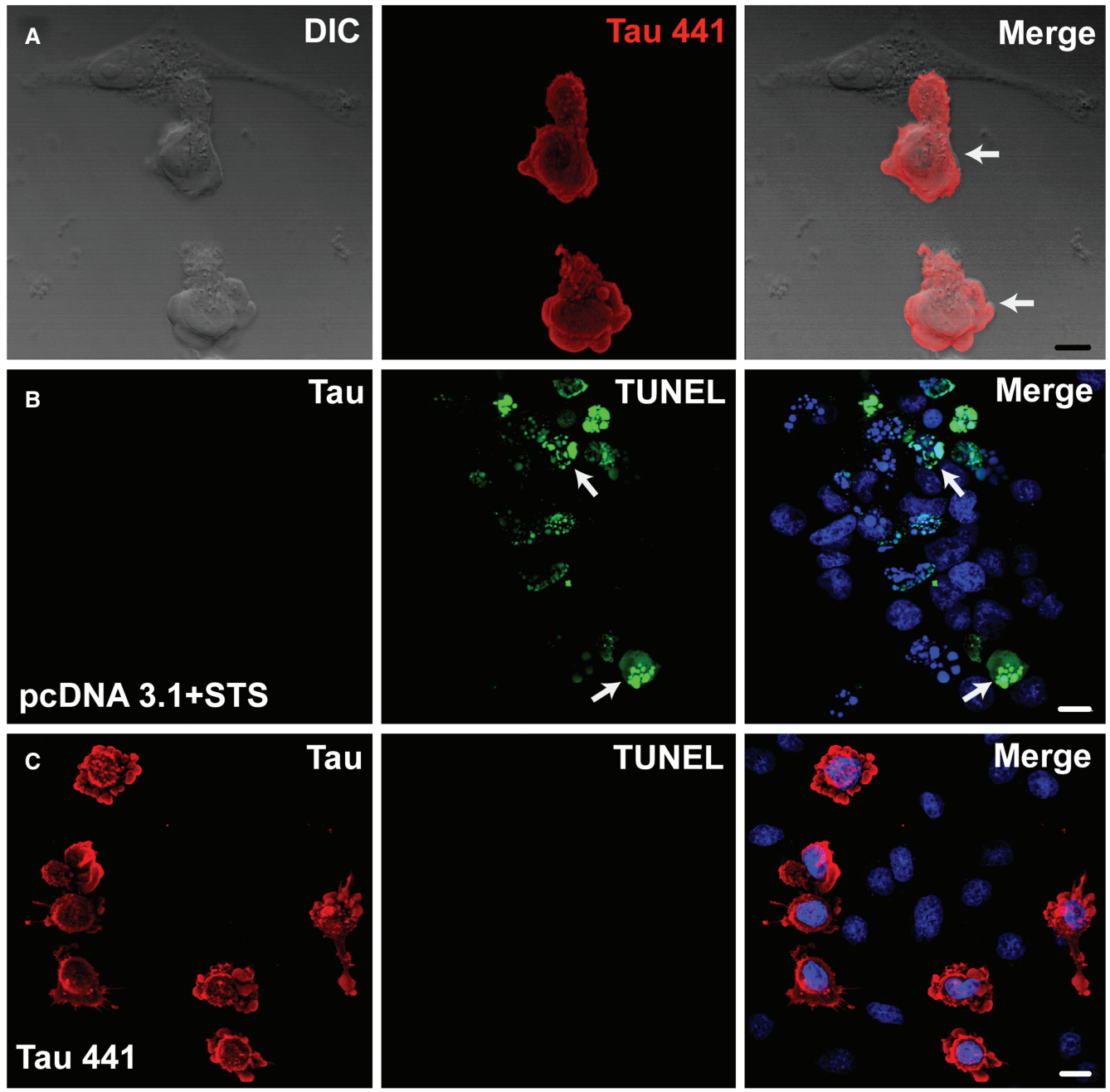

D

E
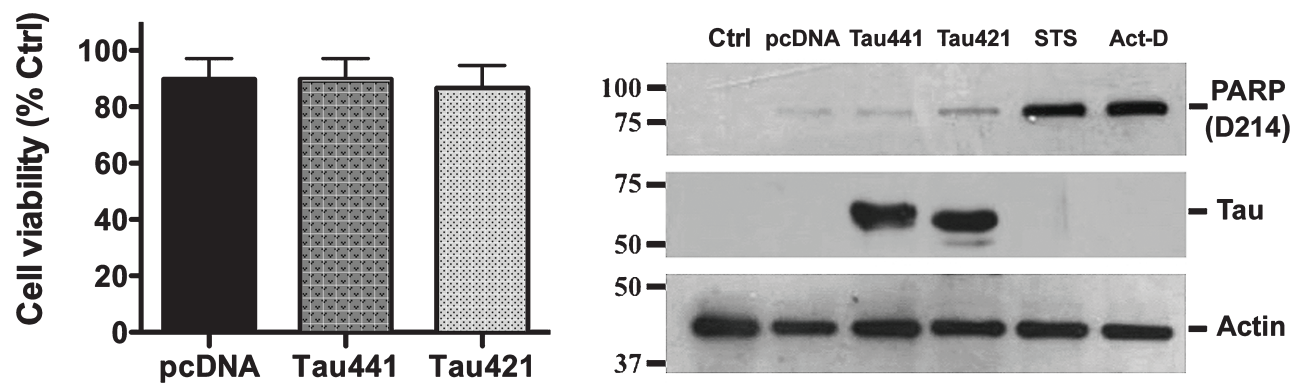

Fig. 2. PM blebbing of Tau-expressing cells is not associated with apoptosis. A) Differential interference contrast (DIC) microscopy allows visualizing the change of shape and volume of Tau441-expressing cells. Immunolabeling with Tau-5 confirms the expression of Tau in C6glial cells undergoing PM blebbing (arrows). C6-glial cells only transfected with the empty vector were pretreated with $1 \mu \mathrm{M}$ staurosporine (STS) and analyzed for the development of apoptotic nuclei with the TUNEL assay and immunolabeled with Tau-46.1 antibody (donated by Dr. V. Lee) to the C-terminus of Tau (B). Apoptotic nuclei are evident (arrows). In C6-glial cells expressing Tau (positive to Tau-46.1) but not treated with STS, TUNEL assay was negative (C). In both conditions, nuclei were counterstained with Hoescht-33258 (blue color in merge). D) MTT assay demonstrated that no changes on cell viability were produced when Tau-expressing cells and empty vector-transfected cells were compared ( $p=0.803$ by one-way ANOVA). E) When non-transfected cells were treated with STS and Act-D $(1 \mu \mathrm{g} / \mathrm{mL})$, the apoptotic PARP $\left(\mathrm{Asp}^{214}\right.$ ) cleavage product was significantly generated, but this was not the case for non-treated C6 cells expressing either Tau441 or Tau421. No degradation of Actin was observed in total extracts from Tau441- and Tau421-expressing cells. Scale bar in A: $10 \mu \mathrm{m}$; in B and C: $15 \mu \mathrm{m}$. 
To further discard the possibility that PM blebs formation was the result of Tau-induced apoptosis, we evaluated the formation of proteolytic products of the activity of the Caspases, such as Asp ${ }^{214}$-cleaved Poly (ADP)-ribose polymerase (PARP) in Tau-expressing and non-transfected C6 cells.

By employing a specific antibody to Asp ${ }^{214}$ cleaved PARP in western blotting (WB) analysis of cells extracts, only a faint band corresponding to this product was observed in both Tau441 and Tau421expressing cell extracts (upper panel, Fig. 2E). This product is less detected in non-transfected cells. For comparative purpose, an increased band corresponding to Asp $^{214}$-cleaved PARP is observed in non-transfected cells induced to apoptosis with either STS $(1 \mu \mathrm{M})$ or Act-D $(1 \mu \mathrm{g} / \mathrm{mL})$ (last two rows, upper panel, Fig. 2E). The expression level of Actin was not altered under any condition (lower panel, Fig. 2E). These results indicate that PM blebs do not originate as apoptotic consequences in Tau-expressing cells.

\section{Plasma membrane blebbing in Tau-transfected C6-glial cells depends on F-Actin remodeling}

Because the Actin cytoskeleton has been involved in dynamic changes of the PM in several types of cells [39], we evaluated whether this fibrillary component was affected in Tau-expressing C6-glial cells. For this purpose, these cells were processed for immunofluorescence with the polyclonal antibody to Tau in combination with Rhodamine-phalloidin, a specific fluorescent marker of F-Actin [40]. As illustrated in Fig. 3A, cells not expressing Tau display spindlelike morphology evidenced by a cortical array of the Actin cytoskeleton and Actin-conformed stress fibers (arrowheads). In contrast, in both Tau441- and Tau421-expressing cells, strong PM blebbing is produced in close association with changes in F-Actin distribution (red channel, Fig. 3B, C). Under this condition, Actin-stress fibers disappeared and the cortical pool of F-Actin now surrounded the large number of blebs emerging from the PM (arrows, Fig. 3B, C). It appears that Tau-induced remodeling of the Actin cytoskeleton is involved in PM blebbing. To evaluate this possibility, we treated Tau-expressing cells with $20 \mu \mathrm{M}$ Cytochalasin-D (a depolymerization agent of F-Actin) for $30 \mathrm{~min}$, and both the integrity of this component and the formation of PM blebs were analyzed by immunofluorescence.

As presented in Fig. 3D, when Tau441-expressing cells were incubated with Cytochalasin-D, formation of PM blebs was prevented (arrow in green channel, Fig. 3D) in close association with disruption of the F-Actin cytoskeleton (red channel, Fig. 3D). In the majority of cells, only a positive pool of Actin remains in polarized clusters (yellow arrow, Fig. 3D). To further validate the contribution of the F-Actin cytoskeleton to the formation of PM blebs, Cytochalasin-D was washed away from treated Tau-expressing cells, and $30 \mathrm{~min}$ later; the Actin cytoskeleton was reorganized in close association with the formation of PM blebs (yellow arrows, Fig. 3E). In non-transfected cells, the Actin cytoskeleton is restored in normal cortical distribution (asterisk, Fig. 3E). Similar results were observed when Tau421-expressing cells were treated and washed with this drug (data not shown). Significant differences among Cytochalasin-D-treated, Cytochalasin-D-treated and washed, and non-treated C6 cells are depicted in Fig. 4A.

To further analyze the contribution of both Tubulin and Actin cytoskeleton components to PM blebbing, C6-glial cells not expressing Tau (Fig. 5) were treated with $10 \mu \mathrm{M}$ Taxol, a microtubule polymerization agent, to mimic the Tau-induced microtubule bundling effect. Taxol treatment for $3 \mathrm{~h}$ promoted the formation of thick microtubule bundles (arrows, Fig. 5B), but not the formation of PM blebs. The FActin cytoskeleton remains unaltered in these cells, with normal distribution along the cell cortex (asterisk, Fig. 5B). For comparative purpose, the normal cytoskeleton in empty-vector transfected cells is depicted in Fig. 5A.

In contrast, when the normal microtubule network was disrupted in these cells due to incubation with $5 \mu \mathrm{M}$ Nocodazole, PM blebbing, and changes in cortical F-Actin organization were also produced (arrows, Fig. 5C); likewise, this was observed in Tau-expressing cells (arrows, Fig. 5D). Quantitative analysis of these effects is shown in Fig. 4B. These results may indicate that abnormal bundling of microtubules specifically induced by Tau promotes a reassembly of the F-Actin that gives rise to the formation of PM blebs.

\section{Tau-induced plasma membrane blebbing is associated with activation of the Rho-GTPase-ROCK pathway}

In different eukaryotic cells, stabilization of the microtubule lattice is a regulated process that depends on the binding of several microtubule-associated proteins (MAPs) [41]; however, additional molecules may also bind to these structures with a double 

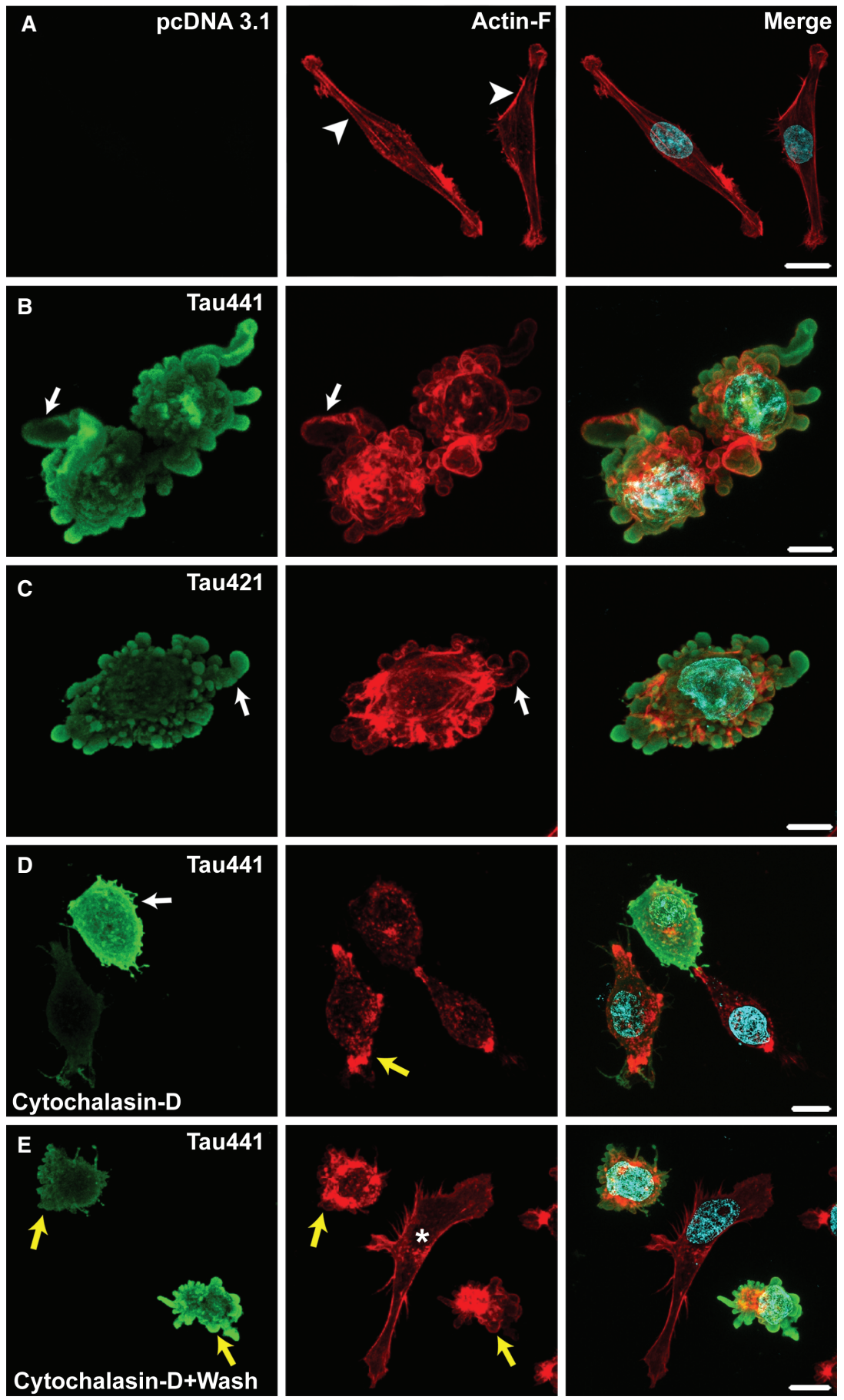

Fig. 3. Tau-induced PM blebbing is caused by remodeling of the F-Actin cytoskeleton. In all panels, Tau441 and Tau421 were recognized with a polyclonal antibody to Tau (green) and the F-Actin cytoskeleton with Rhodamine-phalloidin (red). Nuclei stained with Hoechst-33258 are included in the merge channel (light blue). Note the clear remodeling of F-Actin cytoskeleton in close association with the formation of cortical blebs in both Tau441- (B) and Tau421- (C) expressing C6-glial cells (arrows). F-Actin depolymerization with Cytochalasin-D $(20 \mu \mathrm{M})$ rescues the normal phenotype of C6-glial cells, with less formation of PM blebs (arrow in D). When Cytochalasin-D is washed from the cells, both F-Actin remodeling and PM blebbing are reverted in Tau-expressing cells (yellow arrows in E). In A, for comparison, C6 cells are transfected with the empty vector and a normal F-Actin cytoskeleton is depicted (arrowheads). Scale bars: $20 \mu \mathrm{m}$ in A; $8 \mu \mathrm{m}$ in $\mathrm{B} ; 9 \mu \mathrm{m}$ in $\mathrm{C}$, and $15 \mu \mathrm{m}$ in $\mathrm{D}$ and $\mathrm{E}$. 
A

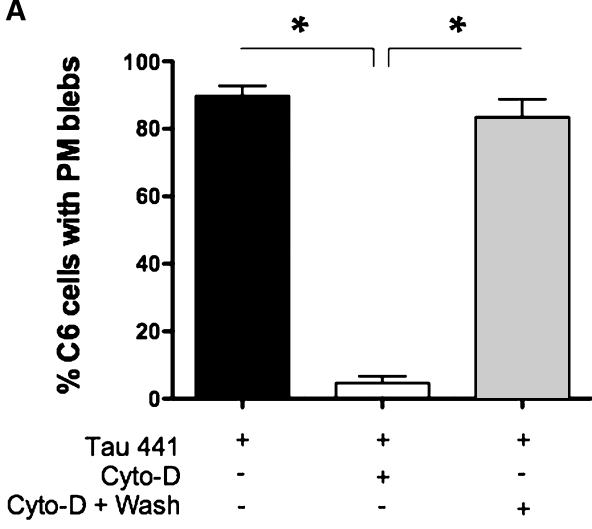

B

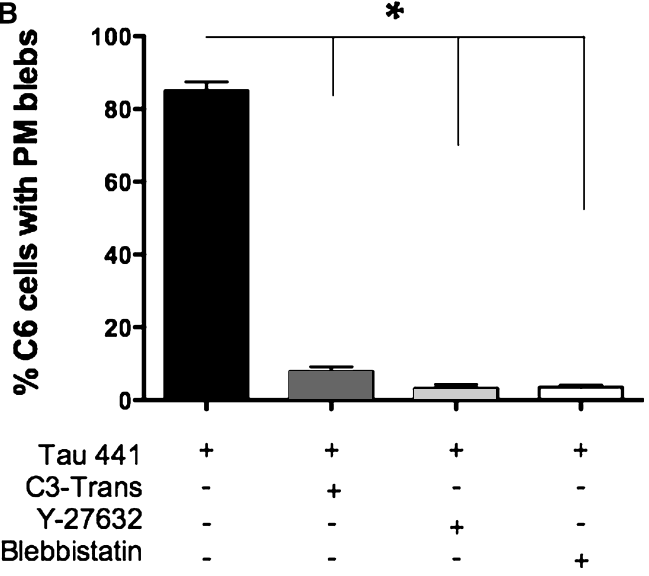

C

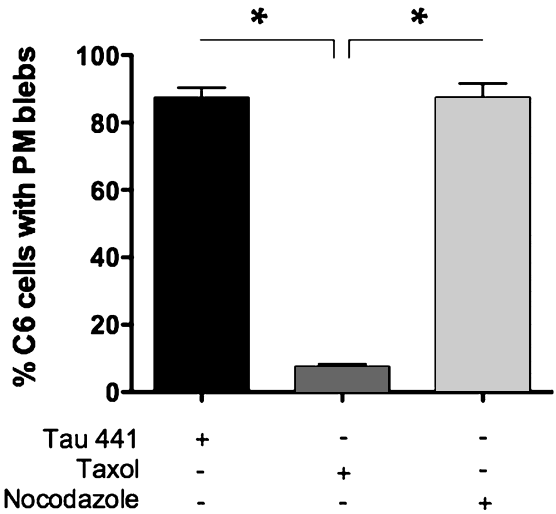

Fig. 4. PM blebbing in Tau441-expressing C6-glial cells is affected by drugs that interfere with the organization and remodeling of F-Actin and Tubulin cytoskeletons. A) The number of Tau-expressing C6-glial cells that developed PM blebs is reduced to 5\% when Cytochalasin-D $(20 \mu \mathrm{M})$ is incubated in the growth media for $30 \mathrm{~min}$. After $30 \mathrm{~min}$ of Cytochalasin-D washing, approximately $85 \%$ of the cells expressing Tau441 again came to develop PM blebs. B) Non-Tau-expressing cells were independently incubated with Taxol (10 $\mu$ M) or Nocodazole $(5 \mu \mathrm{M})$, and the induction on PM blebs was compared to that produced by Tau-expressing cells. Nocodazole- but not Taxol-treatments produced PM blebs in more than $80 \%$ of the cells analyzed. C) When C6 cells expressing Tau441 were incubated with either C3-transferase $(0.5 \mu \mathrm{g} / \mathrm{mL})$ (to inhibit RhoA-GTPase activity), Y-27632 (10 $\mu \mathrm{M})$ (to inhibit ROCK), or Blebbistatin (10 $\mu \mathrm{M})$ (to inhibit Myosin-II activity), the number of cells showing PM blebs was significantly reduced in comparison to non-treated cells. ${ }^{*} p<0.0001$, by one-way Analysis of variance (ANOVA) and consecutive Tukey's multiple comparison test.

purpose as follows: i) contribution to microtubule stabilization, and ii) transient immobilization for selfinactivation. GEF-H1 is one of these molecules that, in turn, actives a small GTPase referred to as RhoA [42]. Bound to microtubules, GEF-H1 is inactivated; however, when the microtubule depolymerizes, GEF$\mathrm{H} 1$ is released into the cytoplasm, wherein it actives GTPase-RhoA in a downstream sequence. Because GEF-H1 is a relevant factor for microtubule stabilization, we evaluated the expression and distribution of this factor in Tau-expressing C6-glial cells showing PM blebs.

As depicted in Fig. 6A, in C6 cells with no Tau expression, the majority of the GEF-H1 is observed in close association with the microtubule lattice (arrows). Bound to microtubules, GEF-H1 immunostaining appears to emulate a fibrillary appearance. In contrast, when Tau-expressing cells were analyzed under the same immunostaining protocol, the majority of GEF-H1 labeling is observed in association with thick rings of microtubule bundles (arrowheads, Fig. 6B); however, some amount of immunodecorated GEF-H1 also remains free in the cytoplasm and is distributed to the PM blebbing area (arrows, Fig. 6B). The latest effect was not produced by Taxolinduced microtubule bundling, and the entire pool of GEFH-1 remains bound to these polymerized structures (arrows in Fig. 6C-D).

Because these results indicate that some amount of GEF-H1 is displaced from the microtubule 

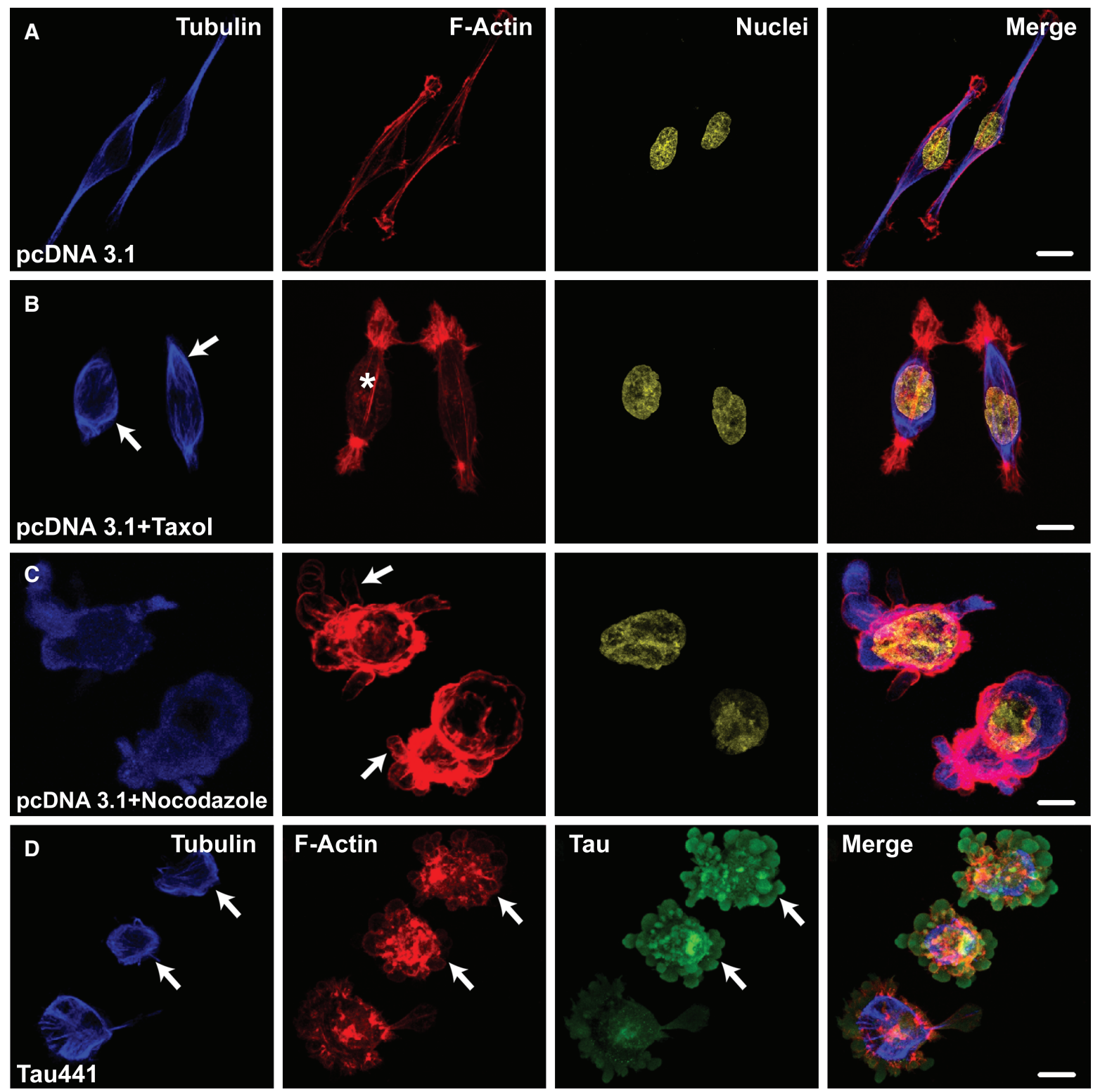

Fig. 5. In non-Tau-expressing C6-glial cells, Taxol induced the formation of microtubule bundle, but not PM blebbing. In all panels, Tubulin and F-Actin were detected with a monoclonal antibody to $\alpha$-Tubulin and Rhodamine-phalloidin, respectively. In panels A-C, nuclei were identified by Hoechst-33258 staining (in yellow pseudocolor). Normal morphology of C6-glial cells is displayed in panel A. When non-Tauexpressing C6 cells were incubated with Taxol $(10 \mu \mathrm{M})$, Tubulin bundling was observed (arrows in B), but neither F-Actin remodeling nor PM blebbing were visualized (asterisk). In contrast, when cells were treated with Nocodazole $(5 \mu \mathrm{M})$, microtubules were depolymerized and both F-Actin remodeling and PM blebbling were also evidenced (arrows, in C). D) In comparison, Tau-induced microtubule bundling in C6-glial cells leads to the formation of PM blebs and F-Actin remodeling (arrows). Tau441 was visualized with a rabbit polyclonal antibody to Tau (see Table 1). Scale bars: $20 \mu \mathrm{m}$ in A; $7 \mu \mathrm{m}$ in C, and $13 \mu \mathrm{m}$ in B and D.

lattice to the cytoplasm under Tau expression, this Rho exchange factor might in turn catalytically activate distinct Rho GTPases, such as RhoA [43], which participates in a catalytic pathway that regulates membrane-Actin cortex interactions for cell motility [44-48]. To probe this, we assessed the role of
RhoA in the formation of PM blebs in Tau-expressing cells by incubating these with the exoenzyme C3transferase, an ADP-Ribosyl Transferase (ADPRT) that selectively ribosylates Rho proteins in the effector-binding domain on asparagine ${ }^{41}$, rendering them inactive [37]. In C6 cells with no expression 


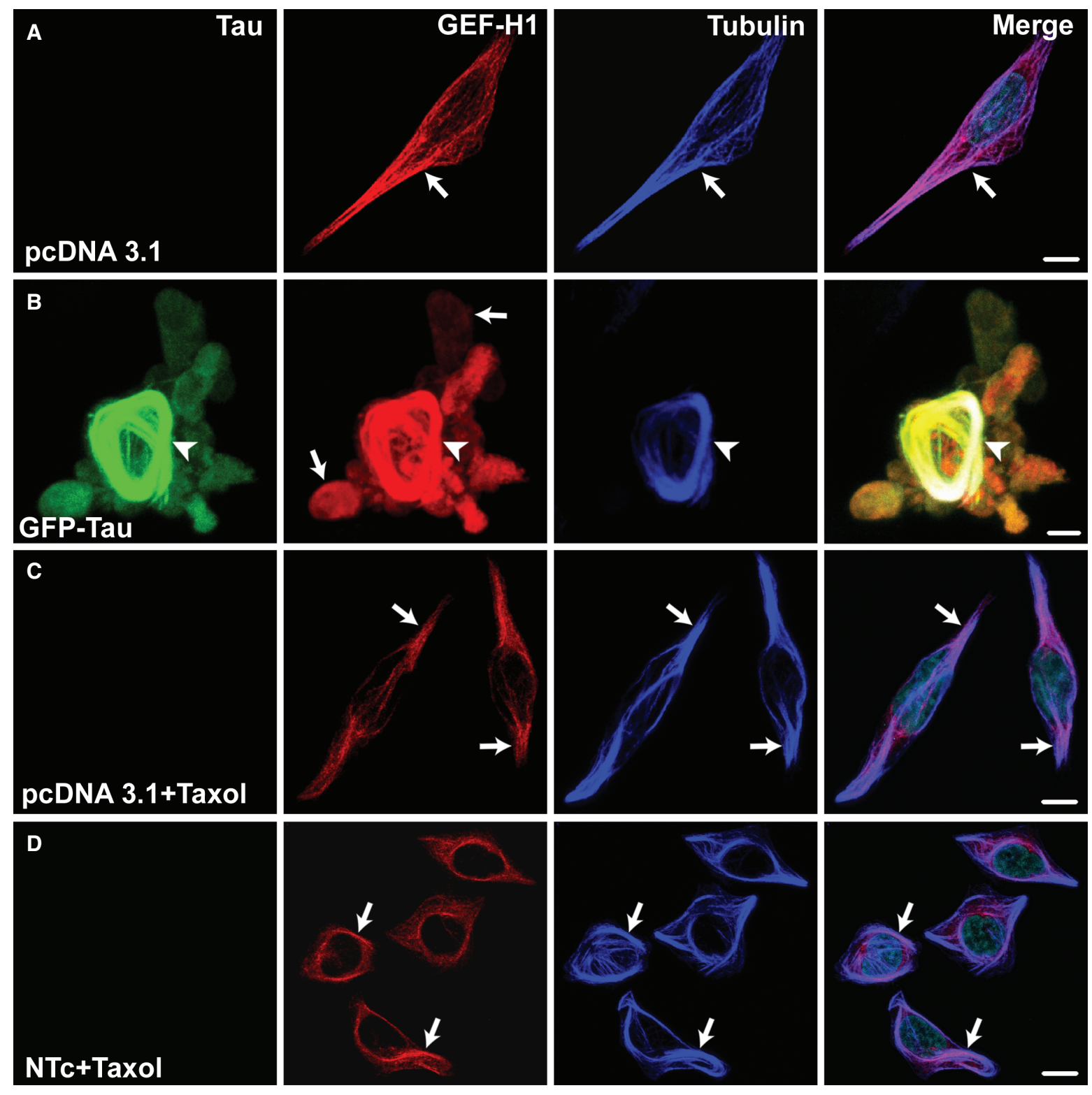

Fig. 6. In C6-glial cells, expression of Tau produces some release of GEF-H1 from microtubules into the cytoplasmic space. A) In non-Tauexpressing cells, GEF-H1 (recognized with a rabbit polyclonal antibody to GEF-H1) is closely associated with microtubules (recognized with a monoclonal antibody to $\alpha$-Tubulin). The nucleus stained with Hoechst-33258 is included in the merge channel. B) When Green fluorescent protein-fused Tau (GFP-Tau441) is expressed, triple co-localization is observed among Tau, GEF-H1, and polymeric Tubulin (arrowheads); however, some amount of GEF-H1 labeling is also present in the cytoplasmic space (arrows). No evidence of free cytoplasmic GEF-H1 is found when the microtubule bundling effect was induced with Taxol in cells with no expression of Tau (C: empty vector transfected cells; D: non-transfected cells [NTc]). Most of the labeling with anti GEF-H1 colocalizes with polymeric $\alpha$-Tubulin in these cells (see merge in $\mathrm{C}$ and $\mathrm{D}$ ). Arrows in $\mathrm{C}$ and $\mathrm{D}$ indicate strong sites of colocalization. Scale bars: $10 \mu \mathrm{m}$ in A and C, $3 \mu \mathrm{m}$ in B, $15 \mu \mathrm{m}$ in D.

of Tau, incubation with C3-transferase $(0.5 \mu \mathrm{g} / \mathrm{mL})$ for $48 \mathrm{~h}$ did not show any alteration in the normal organization of the cytoskeleton components and cell morphology (Fig. 7A). In comparison with the membrane blebbing formation observed in Tau-expressing cells (Fig. 7B), when C3-transferase was incubated while Tau expression began in a separate group of transfected cells, no evidence of PM blebbing was observed during $48 \mathrm{~h}$ of treatment (green channel, Fig. 7C). Concomitantly in these C3-transferasetreated C6 cells, the F-Actin cytoskeleton did not show any cortical remodeling associated with the 

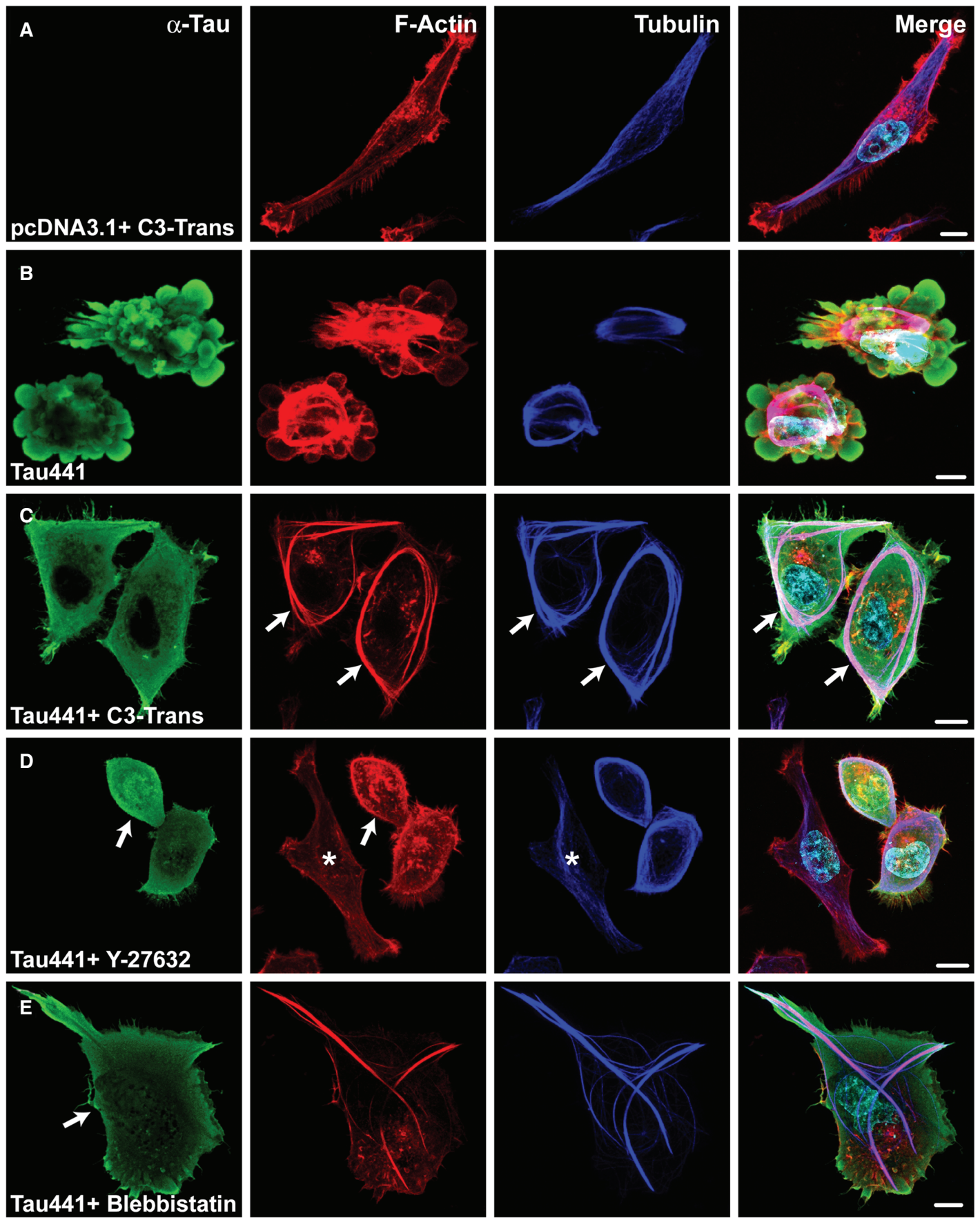

Fig. 7. PM blebbing and F-Actin remodeling in Tau-expressing C6-glial cells are regulated by the RhoA-GTPase-ROCK pathway. In all panels, Tubulin, F-Actin, and Tau441 were detected with a monoclonal antibody to $\alpha$-Tubulin, Rhodamine-phalloidin, and a rabbit polyclonal to Tau, respectively. In the merge channel, nuclear staining with Hoechst-33258 is included. In A, non-Tau-expressing C6 cells were incubated with C3-transferase $(0.5 \mu \mathrm{g} / \mathrm{mL})$, a RhoA inhibitor, and no morphological changes are observed. In B, Tau441-expressing cells show PM blebbing, F-Actin remodeling, and microtubule bundling. C) When these cells were treated with C3-transferase, the abnormal phenotype showing PM blebs associated with F-Actin remodeling was avoided. Similarly, this abnormal phenotype was prevented when Tau441expressing C6 cells were incubated with either $10 \mu \mathrm{M}$ Y-27632, an inhibitor of ROCK (D), or $10 \mu \mathrm{M}$ Blebbistatin, a Myosin-II inhibitor (E). Under incubation with these inhibitors, the microtubule bundling induced by Tau was not altered and notably, it is more evident how the F-Actin cytoskeleton reorganizes according to the pattern displayed by microtubules (arrows, in C). Scale bars: $10 \mu \mathrm{m}$ in A, D and E; $6 \mu \mathrm{m}$ in $\mathrm{B}$, and $11 \mu \mathrm{m}$ in $\mathrm{C}$. 
formation of PM blebs (red channel, Fig. 7C). Instead, this cytoskeletal component appears to adopt a new structure that is closely associated with microtubule bundles (arrows, Fig. 7C).

Because this result indicates that activated-RhoA participates in F-Actin and PM remodeling in Tauexpressing cells, we evaluated whether this GTPase acts through the downstream effector ROCK to increase PM blebbing. To accomplish this, while Tau expression began, transfected-C6 cells were co-incubated with Y-27632 ( (+)- (R)-trans-4(1-aminoethyl)-N- (4-pyridyl) cyclohexanecarboxamide+++dihydrochloride) $(10 \mu \mathrm{M})$, a widely used specific ROCK inhibitor [38], and both F-Actin remodeling and PM blebbing were evaluated and compared with non-treated Tau-expressing C6 cells.

In accordance with Fig. 7A, in cells with no expression of Tau, no changes in either F-Actin organization or in the general morphology of the cells were visualized during $48 \mathrm{~h}$ of incubation with Y-27632 (not shown). In contrast, both the PM blebbing and F-Actin remodeling observed in Tau-expressing cells (Fig. 7B) were reverted when Y-27632 was included in the incubation media (arrows, Fig. 7D). Note that cells with no expression of Tau are unaffected by this treatment, and both Tubulin and F-Actin cytoskeletons remain unaltered (asterisks, Fig. 7D). Under either C3-transferase or Y-27632 treatments, the Tau-promoted microtubule bundling effect is not disturbed (see blue channel, Fig. 7C, D), which emphasizes the specificity of these drugs in regulating F-Actin remodeling. In control experiments, the rescued effects of both C3-transferase and Y-27632 in avoiding PM blebbing and F-Actin remodeling were not sustained for long when these drugs were washed from the cells, thus reestablishing the abnormal phenotype produced by the expression of Tau (not shown). Quantitative data significantly representing the effect of the previously mentioned inhibitors are presented in Fig. 4C. Because Actin-myosin interactions may take place in the Tau-induced PM blebbing, Tau-expressing C6 cells were incubated with Blebbistatin $(10 \mu \mathrm{M})$, a non-muscle Myosin-II-specific inhibitor [49], to validate the participation of MyosinII in this process. As it was expected, the Tau-induced PM blebbing was avoided (arrow, Fig. 7E), likewise the cortical distribution of F-Actin mediating the formation of PM blebs (Fig. 7E). Quantitative data representing the significance of this effect is presented in Fig. 4C.

All of the previously mentioned results indicate that PM blebbing and F-Actin cytoskeleton remodeling are produced by Tau expression through activation of the GEF-H1-RhoA-ROCK pathway.

To give evidence for physiological alterations of the abnormal phenotype observed in C6-glial cells expressing Tau, we evaluated their migration in vitro by using a scratch-wounded assay. As shown in Fig. 8A, after stimulation with high concentrations of FBS, significant amount of empty-vector-transfected cells migrate to the wounded area to occupy the available space (arrowheads). By contrast, when Tau441-expressing cells were also stimulated, only few amounts of these cells migrate to the wounded area (arrows). Quantitatively, less than 20\% of the cells that express Tau migrated to this area. This result indicates that Tau-induced abnormalities in the cytoskeleton and PM, are also accompanied by physiological alteration in the motility of C6 glial cells.

\section{DISCUSSION}

In the present study, we sought evidence to better understand whether accumulation of Tau in glial cells, as it occurs in several tauopathies, produces alterations in cell functioning, as has been reported for neurons.

The major aim was to evaluate whether fulllength Tau and its $\mathrm{Asp}^{421}$-truncated variant induce alterations in cell morphology, particularly in the cytoskeleton and PM integrity, when transiently expressed in C6-glial cells. Our results indicated that both Tau variants produced strong PM blebbing and F-Actin cytoskeleton remodeling. We focused on some intracellular mechanisms leading to F-Actin remodeling, and found that it is produced by indirect activation of the GEF-H1-RhoA-ROCK pathway. All of these actions were initiated by abnormal, induced MT bundling and cytoplasmic release of GEF-H1.

We found that neither full-length Tau nor Asp ${ }^{421}$ truncated Tau produced significant cell death when expressed in glial C6 cells (Fig. 2), contrasting with early evidence reporting immediate induction of apoptosis by $\mathrm{C}$-terminus truncated Tau variants [13, $50,51]$. However, disturbance in the organization and functioning of distinct organelles has been attributed to truncated Tau variants as a gain of toxic functions $[10,11,52]$ and, as we previously showed, this occurred in neurons [18], in the present study we also corroborated that expression of $\mathrm{Asp}^{421}$-truncated and non-truncated Tau produced abnormal bundling of microtubules in C6-glial cells (Fig. 1A, B). In agreement with preceding studies $[19,20,53]$, increased 

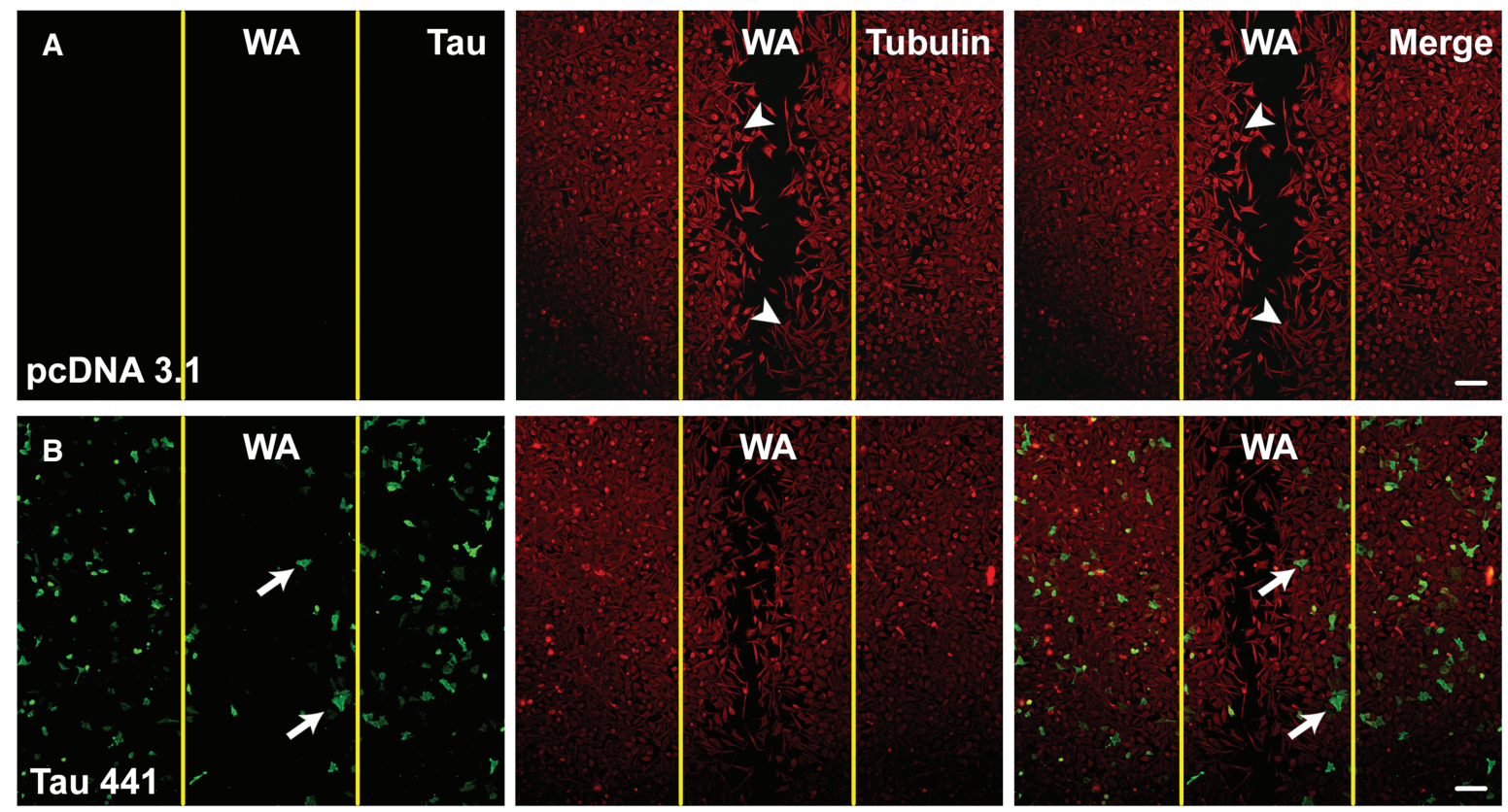

Fig. 8. Tau expressing cells show reduced migration in a scratch-wounded assay. A) $48 \mathrm{~h}$ after empty-vector transfected cell cultures were scratch-wounded, C6 cells migrated to the wounded area (WA) (arrowheads). C6 cells were immunolabeled with a monoclonal antibody to $\alpha$-Tubulin. Yellow lines indicate the initial border of the scratched area. B) When Tau-expressing cell cultures were scratch-wounded, a few amount of these cells migrated to the WA (arrows) during $48 \mathrm{~h}$. Scale bars: $100 \mu \mathrm{m}$.

microtubule bundling in C6-glial cells was the result of the binding of Tau to these structures (Fig. 6B). The biological consequences of this action can be reflected in changes in the distribution and transport of several membranous elements inside the cells [23]. As an illustration of this action, in Tau-expressing rat astrocytes, increased bundling of microtubules was also reported but in addition a decrease in kinesindependent trafficking of membranous elements and collapse of the intermediate filament network was also evidenced [34].

On the other hand, the formation of extensive PM blebs in Tau-expressing C6-glial cells (Figs. 1 and 2) is a remarkable finding that has not been commonly observed in distinct cellular contexts, with the exception of one report, in which a few examples of similar structures, referred to as Tau-positive blobs, were only considered sites of peripheral accumulation of Tau [34]. Under the expression of Tau, we evidenced a further formation of PM blebs that should be considered more of a pathological effect altering the normal architecture of C6-glial cells. In this regard, and despite the morphological similarities, it is unlikely that Tau-induced PM blebbing represent the formation of apoptotic bodies, because no evidence of apoptotic markers or changes in cell survival were found in either Tau-expressing or nontransfected C6-glial cells (Fig. 2). We consider that PM blebbing in glial cells would represent a pathological action that might alter several properties of the membrane, such as permeability, fluidity, signaling, protein localization, and cytoskeletal anchorage, thus severing the global functioning of this cellular type. We demonstrated at least that migration in Tau-expressing C6-glial cells is physiologically compromised. Because of the pathological consequences of this action, in this study we further characterized the mechanism by which Tau induced PM blebbing in C6-glial cells.

\section{PM blebbing in Tau-expressing cells depends on F-Actin cytoskeleton remodeling}

Because PM blebbing represented a specific effect produced by Tau expression and due to that microtubule bundles were not localized in association with these blebs, we searched for alterations in the organization of the F-Actin cytoskeleton, which is known to regulate cell shape and dynamics [39]. In astrocytic cells, the Actin cytoskeleton is involved in additional functions, such as calcium mobilization, signaling, glutamate uptake, and the hormone 
modulation of cell growth [54-56]. We observed, in C6-glial cells, that the normal F-Actin cytoskeleton is distributed cortically and is localized in stress fibers and focal adhesions that attach the cell surface to the substrate [57]. Because this F-Actin meshwork was dramatically remodeled in Tau-expressing C6 cells and observed in close association with emerging PM blebs (Fig. 3), we conclude that this type of cytoskeleton regulates the formation of these abnormal protrusions of the PM. This statement was corroborated when Tau-expressing C6 cells were incubated with Cytochalasin-D, a drug that depolymerizes the F-Actin cytoskeleton [58], and no formation of PM blebs was observed (Fig. 3D). Moreover, the reversibility by which PM blebs were formed again when Cytochalasin-D was eliminated from the media of the cells clearly demonstrates the regulatory role of F-Actin in conducting the formation of these abnormal structures. This result is in agreement with early evidence proposing that the Actin-myosin system is the driving power that promotes cell contraction and the formation of PM blebs and apoptotic bodies under physiological and pathological conditions in response to different stimuli $[59,60]$.

\section{Tau-induced PM blebs are formed by activation of RhoA-GTPase and ROCK}

PM blebbing is a dynamic process implicated in cytokinesis and cell movement, but also in pathological conditions, such as apoptosis and cancer cell invasion. Several studies have demonstrated that PM blebbing depends on the promotion of F-Actin-myosin interactions, which is regulated by RhoGTPaseROCK signaling [44-47]. In our study, we corroborated that PM blebbing in Tau-expressing C6 cells was also regulated by RhoA-GTPase and ROCK signaling, because the addition of their specific inhibitors, C3-transferase and Y-27632, respectively, avoided the formation of these structures (Figs. 7C, D). ROCK is a major effector of RhoA-GTPase, and it was initially characterized for its role in mediating the formation of RhoA-induced stress fibers and focal adhesions [61, 62]. ROCK is a serine/threonine kinase that can directly phosphorylate the Myosin light-chain (MLC) or indirectly increase MLC phosphorylation (MLC-pp) by inactivating the myosin phosphatase [63, 64]. In our Tau-expressing C6-glial cells, we would expect that active ROCK would contribute to F-Actin-myosin force generation, causing blebs to protrude through MLC-pp. Confirmation of F-Actin-myosin interaction during Tau-induced PM blebbing was obtained when cells were incubated with Blebbistatin, a specific inhibitor of Myosin-II activity [49], and neither F-Actin remodeling nor PM blebs formation were observed (Fig. 4C).

Because F-Actin remodeling is involved in the formation of distinct types of PM protrusions, such as lamellipodia and filipodia that depends on the activation of different GTPases, it was difficult to rule out the participation of Rac- 1 and $\mathrm{Cdc} 42$ in the formation of PM blebs in the C6 cells. However, we discarded this possibility because the inclusion of NSC23766, a specific inhibitor of Rac1 [65], did not affect the formation of PM blebs (data not shown). With these experiments, we emphasize the role of RhoA-GTPase in the regulation the dynamics of F-Actin remodeling associated with the formation of PM blebs that, in our particular case, is not initiated by external stimuli [59, $66,67]$. Instead, this is produced only by the presence of Tau in the cytoplasmic space. This comprises a relevant observation, and we can speculate that, even in the absence of external stimuli, only intracellular accumulation of Tau in glial and neuronal cells occurring in distinct tauopathies may render and initiate pathologic alterations in PM architecture and functioning. Despite the evidence that Tau may interact with Actin under several normal and pathological conditions [25, 28, 31, 32], in our control experiments, we did not find direct interactions among these proteins; however, under incubation with either C3transferase or Y-27632, a close association between F-Actin and microtubule bundles, probably mediated by Tau, was observed. This result supports recent in vitro evidence that Tau can induce guided polymerization of Actin filaments along microtubule tracks $[27,68]$. Whether Tau or other cytoskeletalassociated proteins are responsible for this interaction is another interesting issue for further investigation.

\section{GEF-H1: the link between Tau-induced microtubule bundling and F-Actin-dependent PM bleb formation}

Despite that F-Actin remodeling through activation of the RhoA-GTPase-ROCK pathway was responsible for PM blebbing formation in C6 cells, precisely how this cascade with no extracellular stimuli was initiated, represented a major issue to be addressed. How could Tau, with its increased microtubule-bundling properties, initiate activation of the RhoA-ROCK-Actin-myosin pathway, which mediates PM bleb formation? Given that RhoA does not exhibit clear co-localization to microtubules [69], 
direct interaction between these two participants in activating RhoA is unlikely. However, the participation of additional upstream candidates implicated in the RhoA-ROCK pathway, such as GEF, would address this issue. Of the several classes of GEF, the catalytic activity of GEF-H1 is uniquely regulated by its localization to the microtubules. Depolymerization of microtubules leads to GEF-H1 activation, while relocalization to microtubules inhibits its activity [43]. In this regard, when we analyzed GEF-H1 localization in Tau-expressing C6-glial cells, we found that some of this factor remains bound to the microtubule bundles; however, a free pool of this factor was also observed in the cytoplasm (Fig. 6B). We think that under Tau-expression, the induction of microtubule bundling also leads to the release of the microtubule-bounded GEF-H1 into the cytoplasm, which in turn may active RhoAGTPase and consequently the previously mentioned F-Actin remodeling pathway. This result confronts the traditional statement that depolymerization of the microtubule lattice is the key factor for releasing GEF-H1 into the cytoplasm. Tau-induced microtubule bundling is a specific process for inducing the previously noted effects, because incubation with Taxol to stimulate the same effect was not sufficient to induce the release of GEF-H1 to the cytoplasmic space (Figs. 5B; 6C-D). Because Tau and GEF-H1 share localization in the microtubule bundles (Fig. 6B), it may be possible that the binding of Tau along the microtubule surface in some way displaces some amount of the microtubule-bounded GEF-H1 into the cytoplasm; however, more experiments are required to be conclusive.

Overall, it has been demonstrated that the regulated release of GEF-H1 from microtubules is a recurring mechanism for achieving localized activation of RhoA in several physiological processes [70-72]; however, this regulation is also implicated in the development of numerous pathophysiological conditions, including chronic diarrhea [73], cardiomyopathies [74], and cancer [75]. Tau-induced PM blebbing, responding to changes in the Tubulin and F-Actin cytoskeletons, may then result in a pathological condition that alters the normal functioning of glial cells, thus comprising a relevant factor that contributes to neuronal dysfunction.

In summary, the present study further contributes to the description a new molecular mechanism for Tau-induced neuropathology and degeneration in astrocytes. When expressed in astrocytic C6 cells, Tau toxicity was represented by the formation of abnormal blebs along the PM, associated with remodeling of the Tubulin and F-Actin cytoskeletons. This phenotype was produced by the activation of the RhoA-GTPase-ROCK pathway that regulates

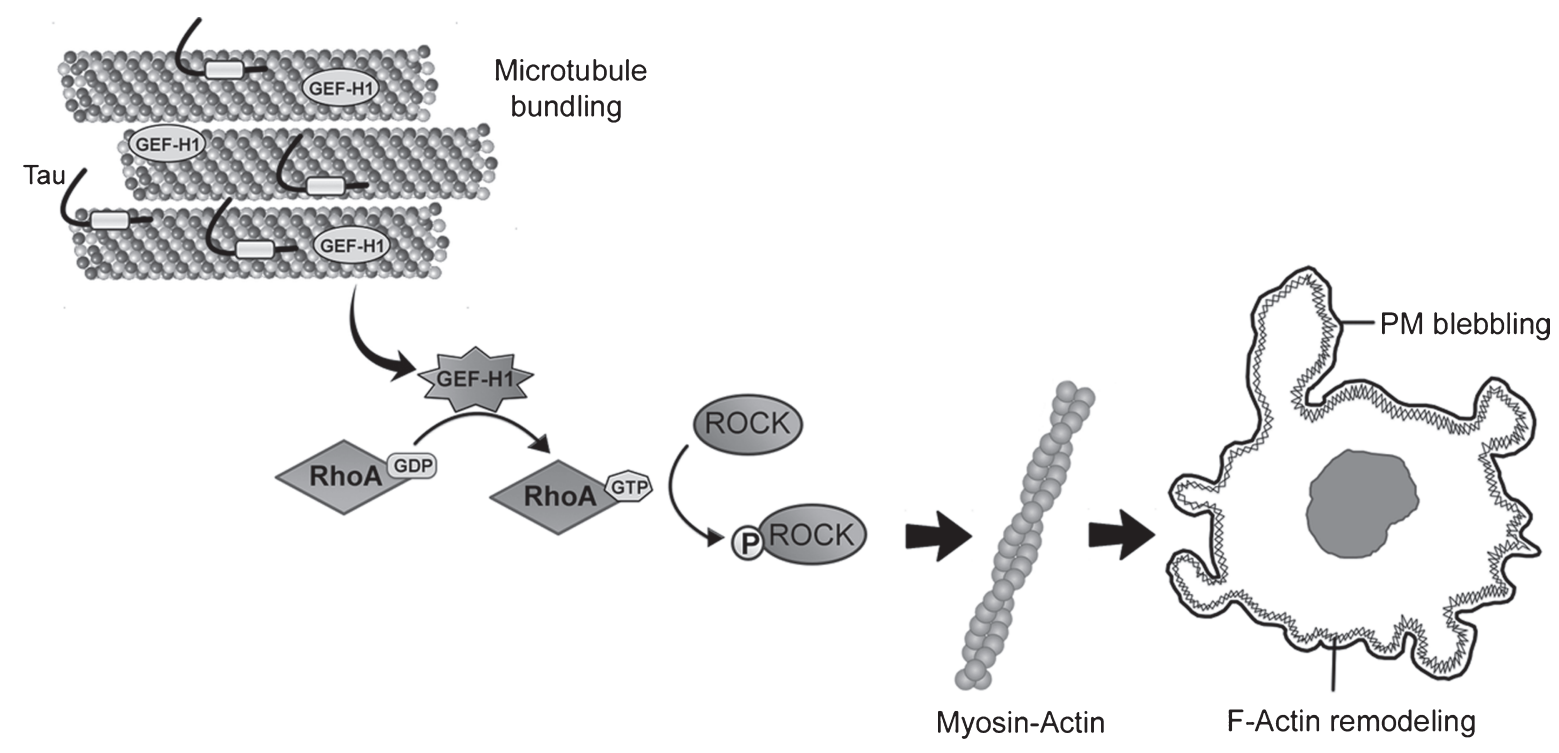

Fig. 9. Proposed mechanism of Tau-induced PM blebbing in glial cells. Increased concentration of Tau in the cytoplasm produces abnormal bundling of microtubules. Although the mechanism by which this occurs remains unknown, microtubule bundling may allow the release of some amount of microtubule-bound GEF-H1 into the cytoplasm, where this nucleotide exchange factor may activate RhoA-GTPase. If so, this GTPase drives the active ROCK to phosphorylate several effectors, including myosin light-chains. This action may promote F-Actinmyosin interactions that lead to remodeling of the F-Actin cytoskeleton and the formation of PM blebs. In AD and other tauopathies, these morphological alterations may take place and contribute to the impairment of glial activity. 
F-Actin-myosin interaction. We think that this cascade is initiated upstream by the release of GEF-H1 into the cytoplasm, due to the abnormal bundling of Tubulin promoted by Tau (Fig. 9). Because glial cells contribute to the neuronal maintenance and survival, Tau-induced alterations in these cells may also account for the neurodegenerative process observed in the brains of individuals suffering from tauopathies.

\section{ACKNOWLEDGMENTS}

Confocal microscopy facilities were provided by the Confocal Microscopy Unit at the Cell Biology Department of CINVESTAV-IPN. We thank to Dr. Margaret Brunner who edited this English-language text. We also express gratitude to Dr. Guadalupe Reyes-Cruz for her assistance and comments on RhoA experiments and Drs. Eduardo Perez Salazar and Pedro Cortes-Reynosa for their assistance in cell migration experiments. This work was supported by CONACyT-Mexico (grant 152535) to Francisco Garcia-Sierra and (scholarship 209642) to Francisco M. Torres-Cruz. Support from GACR P304/12/G069 and ED2.1.00/03.0078 to Daniela Ripova is also acknowledged.

Authors' disclosures available online (http://www. $\mathrm{j}$-alz.com/manuscript-disclosures/15-0396r1).

\section{REFERENCES}

[1] Braak E, Braak H, Mandelkow EM (1994) A sequence of cytoskeleton changes related to the formation of neurofibrillary tangles and neuropil threads. Acta Neuropathol 87, 554-567.

[2] Trojanowski JQ, Shin RW, Schmidt ML, Lee VM (1995) Relationship between plaques, tangles, and dystrophic processes in Alzheimer's disease. Neurobiol Aging 16, 335340; discussion 341-335

[3] Komori T (1999) Tau-positive glial inclusions in progressive supranuclear palsy, corticobasal degeneration and Pick's disease. Brain Pathol 9, 663-679.

[4] Hauw JJ, Verny M, Delaere P, Cervera P, He Y, Duyckaerts $\mathrm{C}$ (1990) Constant neurofibrillary changes in the neocortex in progressive supranuclear palsy. Basic differences with Alzheimer's disease and aging. Neurosci Lett 119, 182-186.

[5] Feany MB, Dickson DW (1995) Widespread cytoskeletal pathology characterizes corticobasal degeneration. Am $J$ Pathol 146, 1388-1396.

[6] Braak H, Braak E (1987) Argyrophilic grains: Characteristic pathology of cerebral cortex in cases of adult onset dementia without Alzheimer changes. Neurosci Lett 76, 124-127.

[7] Odawara T, Iseki E, Kosaka K, Akiyama H, Ikeda $\mathrm{K}$, Yamamoto $\mathrm{T}$ (1995) Investigation of tau-2 positive microglia-like cells in the subcortical nuclei of human neurodegenerative disorders. Neurosci Lett 192, 145-148.
[8] Ghoshal N, Garcia-Sierra F, Fu Y, Beckett LA, Mufson EJ, Kuret J, Berry RW, Binder LI (2001) Tau-66: Evidence for a novel tau conformation in Alzheimer's disease. $\mathrm{J} \mathrm{Neu}$ rochem $\mathbf{7 7}, 1372-1385$.

[9] Krishnamurthy PK, Johnson GV (2004) Mutant (R406W) human tau is hyperphosphorylated and does not efficiently bind microtubules in a neuronal cortical cell model. J Biol Chem 279, 7893-7900.

[10] Quintanilla RA, Matthews-Roberson TA, Dolan PJ, Johnson GV (2009) Caspase-cleaved tau expression induces mitochondrial dysfunction in immortalized cortical neurons: Implications for the pathogenesis of Alzheimer disease. J Biol Chem 284, 18754-18766.

[11] Matthews-Roberson TA, Quintanilla RA, Ding H, Johnson GV (2008) Immortalized cortical neurons expressing caspase-cleaved tau are sensitized to endoplasmic reticulum stress induced cell death. Brain Res 1234, 206-212.

[12] Sato S, Tatebayashi Y, Akagi T, Chui DH, Murayama M, Miyasaka T, Planel E, Tanemura K, Sun X, Hashikawa T, Yoshioka K, Ishiguro K, Takashima A (2002) Aberrant tau phosphorylation by glycogen synthase kinase-3beta and JNK3 induces oligomeric tau fibrils in COS-7 cells. $J$ Biol Chem 277, 42060-42065.

[13] Fasulo L, Visintin M, Novak M, Cattaneo A (1998) Tau truncation in Alzheimer's disease: Expression of a fragment encompassing PHF core tau induces apoptosis in COS cells. Alzheimers Rep 1, 25-32.

[14] Amadoro G, Corsetti V, Florenzano F, Atlante A, Ciotti MT, Mongiardi MP, Bussani R, Nicolin V, Nori SL, Campanella M, Calissano P (2014) AD-linked, toxic NH2 human tau affects the quality control of mitochondria in neurons. Neurobiol Dis 62, 489-507.

[15] Basurto-Islas G, Luna-Munoz J, Guillozet-Bongaarts AL, Binder LI, Mena R, Garcia-Sierra F (2008) Accumulation of aspartic acid421- and glutamic acid391-cleaved tau in neurofibrillary tangles correlates with progression in Alzheimer disease. J Neuropathol Exp Neurol 67, 470-483.

[16] Garcia-Sierra F, Ghoshal N, Quinn B, Berry RW, Binder LI (2003) Conformational changes and truncation of tau protein during tangle evolution in Alzheimer's disease. J Alzheimers Dis 5, 65-77.

[17] Gamblin TC, Chen F, Zambrano A, Abraha A, Lagalwar S, Guillozet AL, Lu M, Fu Y, Garcia-Sierra F, LaPointe N, Miller R, Berry RW, Binder LI, Cryns VL (2003) Caspase cleavage of tau: Linking amyloid and neurofibrillary tangles in Alzheimer's disease. Proc Natl Acad Sci U S A 100, 10032-10037.

[18] Monroy-Ramirez HC, Basurto-Islas G, Mena R, Cisneros B, Binder LI, Avila J, Garcia-Sierra F (2013) Alterations in the nuclear architecture produced by the overexpression of tau protein in neuroblastoma cells. J Alzheimers Dis 36, 503-520.

[19] Samsonov A, Yu JZ, Rasenick M, Popov SV (2004) Tau interaction with microtubules in vivo. J Cell Sci 117, 61296141.

[20] Esmaeli-Azad B, McCarty JH, Feinstein SC (1994) Sense and antisense transfection analysis of tau function: Tau influences net microtubule assembly, neurite outgrowth and neuritic stability. J Cell Sci 107 (Pt 4), 869-879.

[21] Ebneth A, Godemann R, Stamer K, Illenberger S, Trinczek B, Mandelkow E (1998) Overexpression of tau protein inhibits kinesin-dependent trafficking of vesicles, mitochondria, and endoplasmic reticulum: Implications for Alzheimer's disease. J Cell Biol 143, 777-794. 
[22] Trinczek B, Ebneth A, Mandelkow EM, Mandelkow E (1999) Tau regulates the attachment/detachment but not the speed of motors in microtubule-dependent transport of single vesicles and organelles. J Cell Sci 112 (Pt 14), 23552367.

[23] Stamer K, Vogel R, Thies E, Mandelkow E, Mandelkow EM (2002) Tau blocks traffic of organelles, neurofilaments, and APP vesicles in neurons and enhances oxidative stress. J Cell Biol 156, 1051-1063.

[24] Griffith LM, Pollard TD (1982) The interaction of actin filaments with microtubules and microtubule-associated proteins. J Biol Chem 257, 9143-9151.

[25] Correas I, Padilla R, Avila J (1990) The tubulin-binding sequence of brain microtubule-associated proteins, tau and MAP-2, is also involved in actin binding. Biochem $J \mathbf{2 6 9}$, 61-64.

[26] He HJ, Wang XS, Pan R, Wang DL, Liu MN, He RQ (2009) The proline-rich domain of tau plays a role in interactions with actin. BMC Cell Biol 10, 81.

[27] Elie A, Prezel E, Guerin C, Denarier E, Ramirez-Rios S, Serre L, Andrieux A, Fourest-Lieuvin A, Blanchoin L, Arnal I (2015) Tau co-organizes dynamic microtubule and actin networks. Sci Rep 5, 9964.

[28] Henriquez JP, Cross D, Vial C, Maccioni RB (1995) Subpopulations of tau interact with microtubules and actin filaments in various cell types. Cell Biochem Funct 13, 239-250.

[29] Kempf M, Clement A, Faissner A, Lee G, Brandt R (1996) Tau binds to the distal axon early in development of polarity in a microtubule- and microfilament-dependent manner. J Neurosci 16, 5583-5592.

[30] Moraga DM, Nunez P, Garrido J, Maccioni RB (1993) A tau fragment containing a repetitive sequence induces bundling of actin filaments. J Neurochem 61, 979-986.

[31] Frandemiche ML, De Seranno S, Rush T, Borel E, Elie A, Arnal I, Lante F, Buisson A (2014) Activity-dependent tau protein translocation to excitatory synapse is disrupted by exposure to amyloid-beta oligomers. J Neurosci 34, 60846097.

[32] Fulga TA, Elson-Schwab I, Khurana V, Steinhilb ML, Spires TL, Hyman BT, Feany MB (2007) Abnormal bundling and accumulation of F-actin mediates tau-induced neuronal degeneration in vivo. Nat Cell Biol 9, 139-148.

[33] Sharma VM, Litersky JM, Bhaskar K, Lee G (2007) Tau impacts on growth-factor-stimulated actin remodeling. J Cell Sci 120, 748-757.

[34] Yoshiyama Y, Zhang B, Bruce J, Trojanowski JQ, Lee VM (2003) Reduction of detyrosinated microtubules and Golgi fragmentation are linked to tau-induced degeneration in astrocytes. J Neurosci 23, 10662-10671.

[35] Wang L, Jiang Q, Chu J, Lin L, Li XG, Chai GS, Wang Q, Wang JZ, Tian Q (2013) Expression of Tau40 induces activation of cultured rat microglial cells. PLoS One 8, e76057.

[36] Denizot F, Lang R (1986) Rapid colorimetric assay for cell growth and survival. Modifications to the tetrazolium dye procedure giving improved sensitivity and reliability. $J$ Immunol Methods 89, 271-277.

[37] Aktories K, Mohr C, Koch G (1992) Clostridium botulinum C3 ADP-ribosyltransferase. Curr Top Microbiol Immunol 175, 115-131.

[38] Ishizaki T, Uehata M, Tamechika I, Keel J, Nonomura K, Maekawa M, Narumiya S (2000) Pharmacological properties of Y-27632, a specific inhibitor of rho-associated kinases. Mol Pharmacol 57, 976-983.

[39] Zigmond SH (1996) Signal transduction and actin filament organization. Curr Opin Cell Biol 8, 66-73.
[40] Wulf E, Deboben A, Bautz FA, Faulstich H, Wieland T (1979) Fluorescent phallotoxin, a tool for the visualization of cellular actin. Proc Natl Acad Sci U S A 76, 4498-4502.

[41] Dehmelt L, Halpain S (2004) Actin and microtubules in neurite initiation: Are MAPs the missing link? J Neurobiol 58, 18-33.

[42] Birkenfeld J, Nalbant P, Yoon SH, Bokoch GM (2008) Cellular functions of GEF-H1, a microtubule-regulated Rho-GEF: Is altered GEF-H1 activity a crucial determinant of disease pathogenesis? Trends Cell Biol 18, 210-219.

[43] Krendel M, Zenke FT, Bokoch GM (2002) Nucleotide exchange factor GEF-H1 mediates cross-talk between microtubules and the actin cytoskeleton. Nat Cell Biol 4, 294-301.

[44] Sahai E, Marshall CJ (2003) Differing modes of tumour cell invasion have distinct requirements for Rho/ROCK signalling and extracellular proteolysis. Nat Cell Biol 5, 711-719.

[45] Charras GT, Yarrow JC, Horton MA, Mahadevan L, Mitchison TJ (2005) Non-equilibration of hydrostatic pressure in blebbing cells. Nature 435, 365-369.

[46] Gadea G, de Toledo M, Anguille C, Roux P (2007) Loss of p53 promotes RhoA-ROCK-dependent cell migration and invasion in 3D matrices. J Cell Biol 178, 23-30.

[47] Kitzing TM, Sahadevan AS, Brandt DT, Knieling H, Hannemann S, Fackler OT, Grosshans J, Grosse R (2007) Positive feedback between Dia1, LARG, and RhoA regulates cell morphology and invasion. Genes Dev 21, 1478-1483.

[48] Tournaviti S, Hannemann S, Terjung S, Kitzing TM, Stegmayer C, Ritzerfeld J, Walther P, Grosse R, Nickel W, Fackler OT (2007) SH4-domain-induced plasma membrane dynamization promotes bleb-associated cell motility. J Cell Sci 120, 3820-3829.

[49] Straight AF, Cheung A, Limouze J, Chen I, Westwood NJ, Sellers JR, Mitchison TJ (2003) Dissecting temporal and spatial control of cytokinesis with a myosin II Inhibitor. Science 299, 1743-1747.

[50] Fasulo L, Ugolini G, Visintin M, Bradbury A, Brancolini C, Verzillo V, Novak M, Cattaneo A (2000) The neuronal microtubule-associated protein tau is a substrate for caspase-3 and an effector of apoptosis. $J$ Neurochem $\mathbf{7 5}$, 624-633.

[51] Garcia-Sierra F, Mondragon-Rodriguez S, Basurto-Islas G (2008) Truncation of tau protein and its pathological significance in Alzheimer's disease. J Alzheimers Dis 14, 401-409.

[52] Amadoro G, Corsetti V, Stringaro A, Colone M, D'Aguanno S, Meli G, Ciotti M, Sancesario G, Cattaneo A, Bussani R, Mercanti D, Calissano P (2010) A NH2 tau fragment targets neuronal mitochondria at AD synapses: Possible implications for neurodegeneration. J Alzheimers Dis 21, 445-470.

[53] Yu JZ, Kuret J, Rasenick MM (2002) Transient expression of fluorescent tau proteins promotes process formation in $\mathrm{PC} 12$ cells: Contributions of the tau C-terminus to this process. J Neurosci Res 67, 625-633.

[54] Cotrina ML, Lin JH, Nedergaard M (1998) Cytoskeletal assembly and ATP release regulate astrocytic calcium signaling. J Neurosci 18, 8794-8804.

[55] Duan S, Anderson CM, Stein BA, Swanson RA (1999) Glutamate induces rapid upregulation of astrocyte glutamate transport and cell-surface expression of GLAST. J Neurosci 19, 10193-10200.

[56] Sergeeva M, Ubl JJ, Reiser G (2000) Disruption of actin cytoskeleton in cultured rat astrocytes suppresses ATP- and bradykinin-induced $[\mathrm{Ca}(2+)]$ (i) oscillations by reducing 
the coupling efficiency between $\mathrm{Ca}(2+)$ release, capacitative $\mathrm{Ca}(2+)$ entry, and store refilling. Neuroscience $\mathbf{9 7}$, 765-769.

[57] Chen Y, Chou WC, Ding YM, Wu YC (2014) Caffeine inhibits migration in glioma cells through the ROCK-FAK pathway. Cell Physiol Biochem 33, 1888-1898.

[58] Cooper JA (1987) Effects of cytochalasin and phalloidin on actin. J Cell Biol 105, 1473-1478.

[59] Torgerson RR, McNiven MA (1998) The actin-myosin cytoskeleton mediates reversible agonist-induced membrane blebbing. J Cell Sci 111 (Pt 19), 2911-2922.

[60] Coleman ML, Olson MF (2002) Rho GTPase signalling pathways in the morphological changes associated with apoptosis. Cell Death Differ 9, 493-504.

[61] Ishizaki T, Maekawa M, Fujisawa K, Okawa K, Iwamatsu A, Fujita A, Watanabe N, Saito Y, Kakizuka A, Morii N, Narumiya S (1996) The small GTP-binding protein Rho binds to and activates a $160 \mathrm{kDa}$ Ser/Thr protein kinase homologous to myotonic dystrophy kinase. EMBO J 15, 1885-1893.

[62] Leung T, Chen XQ, Manser E, Lim L (1996) The p160 RhoA-binding kinase ROK alpha is a member of a kinase family and is involved in the reorganization of the cytoskeleton. Mol Cell Biol 16, 5313-5327.

[63] Amano M, Ito M, Kimura K, Fukata Y, Chihara K, Nakano T, Matsuura Y, Kaibuchi K (1996) Phosphorylation and activation of myosin by Rho-associated kinase (Rho-kinase). J Biol Chem 271, 20246-20249.

[64] Kimura K, Ito M, Amano M, Chihara K, Fukata Y, Nakafuku M, Yamamori B, Feng J, Nakano T, Okawa K, Iwamatsu A, Kaibuchi K (1996) Regulation of myosin phosphatase by Rho and Rho-associated kinase (Rho-kinase). Science 273, 245-248.

[65] Gao Y, Dickerson JB, Guo F, Zheng J, Zheng Y (2004) Rational design and characterization of a Rac GTPasespecific small molecule inhibitor. Proc Natl Acad Sci U S A 101, 7618-7623.

[66] Hagmann J, Burger MM, Dagan D (1999) Regulation of plasma membrane blebbing by the cytoskeleton. $J$ Cell Biochem 73, 488-499.
[67] Singh VP, McNiven MA (2008) Src-mediated cortactin phosphorylation regulates actin localization and injurious blebbing in acinar cells. Mol Biol Cell 19, 2339-2347.

[68] Mohan R, John A (2015) Microtubule-associated proteins as direct crosslinkers of actin filaments and microtubules. IUBMB Life 67, 395-403.

[69] Michaelson D, Silletti J, Murphy G, D'Eustachio P, Rush M, Philips MR (2001) Differential localization of Rho GTPases in live cells: Regulation by hypervariable regions and RhoGDI binding. $J$ Cell Biol 152, 111-126.

[70] Bakal CJ, Finan D, LaRose J, Wells CD, Gish G, Kulkarni S, DeSepulveda P, Wilde A, Rottapel R (2005) The Rho GTP exchange factor Lfc promotes spindle assembly in early mitosis. Proc Natl Acad Sci U S A 102, 9529-9534.

[71] Birkenfeld J, Nalbant P, Bohl BP, Pertz O, Hahn KM, Bokoch GM (2007) GEF-H1 modulates localized RhoA activation during cytokinesis under the control of mitotic kinases. Dev Cell 12, 699-712.

[72] Ryan XP, Alldritt J, Svenningsson P, Allen PB, Wu GY, Nairn AC, Greengard P (2005) The Rho-specific GEF Lfc interacts with neurabin and spinophilin to regulate dendritic spine morphology. Neuron 47, 85-100.

[73] Matsuzawa T, Kuwae A, Yoshida S, Sasakawa C, Abe A (2004) Enteropathogenic Escherichia coli activates the RhoA signaling pathway via the stimulation of GEF-H1. EMBO J 23, 3570-3582.

[74] Cooper Gt (2006) Cytoskeletal networks and the regulation of cardiac contractility: Microtubules, hypertrophy, and cardiac dysfunction. Am J Physiol Heart Circ Physiol 291, H1003-H1014.

[75] Sahai E, Marshall CJ (2002) RHO-GTPases and cancer. Nat Rev Cancer 2, 133-142.

[76] Carmel G, Mager EM, Binder LI, Kuret J (1996) The structural basis of monoclonal antibody Alz50's selectivity for Alzheimer's disease pathology. J Biol Chem 271, 3278932795 .

[77] Diaz-Barriga F, Carrizales L, Yanez L, Hernandez JM, Dominguez Robles MC, Palmer E, Saborio JL (1989) Interaction of cadmium with actin microfilaments in vitro. Toxicol In Vitro 3, 277-284. 